\title{
Life and FCT failure of yttria- and ceria-stabilized EBPVD TBC systems on Ni-base substrates
}

\author{
Klaus Fritscher \\ Institute of Materials Research, DLR - German Aerospace Center, 51170 Cologne, Germany
}

The lifetime at $1100^{\circ} \mathrm{C}$ of furnace oxidation tested TBC samples having YSZ $\left(\mathrm{ZrO}_{2}-7 \mathrm{wt} \% \mathrm{Y}_{2} \mathrm{O}_{3}\right)$ and $\mathrm{CeSZ}\left(\mathrm{ZrO}_{2}-\right.$ $25 \mathrm{wt} \% \mathrm{CeO}_{2}-2.5 \mathrm{wt} \% \mathrm{Y}_{2} \mathrm{O}_{3}$ ) topcoats on four Ni base alloys including a no-bond coat NiCrAl alloy were studied. The thermally grown oxide (TGO) was investigated by energy dispersive spectroscopy. The outer zone of the TGO revealed preferred enrichment of $\mathrm{Zr}$ and of rare earth elements $\mathrm{Ce}$ and $\mathrm{Y}$ in dependence of the stage of life. The oxygen potential gradients in the TGO have been rated; they are stronger for the YSZ TBC systems than for the CeSZ systems and cause a more intensive interaction of the outer zone alias mixed zone with the metal substrate than with the ceramic topcoat. When comparing the chemical composition data of the mixed zone as a function of the test period, the average lifetime as well as the particular composition of the two topcoats and the refractory element content of the substrates allowed conclusions to be drawn about the mechanisms which influence the lifetime.

Keywords TBC lifetime - Substrate effect - Rare Earth Element effect - Thermally grown oxide · Mixed zone $\cdot$ Electron beam physical vapor deposition

\section{Introduction}

Thermal barrier coatings have been successfully introduced in gas turbine applications for several decades. They commonly consist of a metallic bond coat and a ceramic zirconia-base topcoat. They offer the potential to significantly improve the efficiency of aero engines and stationary gas turbines for power generation [1]. In practice, in particular YSZ stabilized TBCs $\left(\mathrm{ZrO}_{2}-7 \mathrm{wt} . \% \mathrm{Y}_{2} \mathrm{O}_{3}\right)$ have prevailed. The industrial feasibility of coatings by plasma spraying (PS) and electron-beam physical vapor deposition (EBPVD) is of utmost importance for widespread high temperature applications in aviation and electric power generation. Zirconia deposition processes which are a proven and preferred method in industrial practice are mostly done by feeding a plasma spray gun with yttria-stabilized zirconia (YSZ) spray powders; the comparable processes of electron beam evaporation of YSZ on substrates are commonly done via charging compacted ingots consisting of a mixture of yttria and zirconia into an evaporation pool.

Occasionally alternative zirconia-base thermal barrier coatings are mentioned, e.g. CeSZ ceria-yttria stabilized 
zirconia $\left(\mathrm{ZrO}_{2}-25\right.$ wt.\% $\mathrm{CeO}_{2}-2.5$ wt. $\left.\% \mathrm{Y}_{2} \mathrm{O}_{3}\right)$ topcoats. However, coatings made of an oxide mixtures of three components may turn out to be more problematic in the processing and in the operational behavior compared to YSZ, which consists of only two components (see appendix which gives a short description about the EBPVD surfacing of YSZ and CeSZ topcoats). Ceria-modified TBCs made via PS may exhibit an inhomogeneous chemical distribution of the elements, which primarily depends on the scatter in the respective spray powder fractions used [2]. EBPVD CeSZ TBCs show particular fluctuations in composition across the layer thickness which account for a step-wise loss and degradation of the CeSZ topcoat in cyclic burner rig tests [3].

During EBPVD processing of the zirconia-base top layers at high temperatures an oxide interlayer alias a thermally grown oxide (TGO) is growing on a bond coat interlayer. The lower part of the TGO consists of a columnar alumina zone (CAZ). The upper part which has formed first during the early stage of TBC deposition, is an essential interlayer in thermally evaporated zirconia TBC systems. It cares for cohesion between the oxide and metal layers. It is basically an alumina matrix with dispersed zirconia in it, explicitly a mixed zzone (MZ). It hardly changes its geometry in the course of life, but it changes its composition, which is mainly caused by the inclusion of other inter-diffusing elements. They are accumulating in this zone. They stem from the bond coat and substrate alloy base below and the zirconia topcoat composition above. These elements are mostly $\mathrm{Cr}$, rare earth elements like $Y$, and Zr. This behavior is observed in a similar manner in diverse EBPVD TBC systems, provided that both the NiCoCrAlY bond coat and the substrate alloys definitely contain no Hf. In systems containing $\mathrm{Hf}$ as an alloying element or as a co-dopant in the bond coat, a very different structure of the TGO and in the TBC system can be effected. Such a changed structure causes both a different failure mode as well as a greatly different lifetime. These cases are excluded in this study.

The $\mathrm{MZ}$ discloses its central role: the content of the accumulated elements in the $\mathrm{MZ}$ is indicative of the service life. The key elements for YSZ top-coated systems are Y and Zr [4], for CeSZ top-coated systems the elements $\mathrm{Ce}, \mathrm{Y}$ and $\mathrm{Zr}$ [5]. Their content in the $\mathrm{MZ}$ is a characteristic measure of the stage of life [4,5]. They indicate a new way to life prediction for EBPVD TBC systems.

The successive stages of life of early, intermediate and late character are looking very similar within the various NiCoCrAlY bond-coated EBPVD TBC systems albeit extremely differently composed Ni substrates have been used. The stages subdivide the effective lifetime. Although the stages of life are similar to each other, they occur at individually different times. This situation necessitated to find a benchmark for the different sample systems. For reasons of comparability between different samples, their average life has been taken as a 
reference. According to this definition of life the average lifetime (it represents $100 \%$ of the actual life) is referred to as the "relative life"; it refers to the respective stage of life for individual TBC systems on their substrates.

Prior work reports about the extent of accumulation of alloying elements of the substrates in the bond coat of EBPVD TBC systems after short annealing times. A selective accumulation of elements has been determined for refractory elements such as Mo, W, Re and Ta to become established between the substrates and the exterior region of the bond coat, the ratio being about 3 to 1 [6]. A related relationship between increasing refractory element contents in the substrate alloys and decreasing lifetimes of TBC systems was estimated from FCT data [4]. This linkage between refractory element contents in the substrate and the lifetime of TBC systems will be tracked in this study.

The causes of the separation failure of the layers of plasma-sprayed TBC systems are the mechanical stresses stored within this structure. The causes of the failure of EBPVD TBC systems turn out to be different. For YSZ top-coated systems, mechanical failure causes could already be excluded. Instead, chemical causes for the adhesion at the Me / TGO interface were identified to be crucial [4].

Similarly the significance of mechanical causes for FCT failure of EBPVD CeSZ top-coated TBC systems is representable. As stated by Fig. 1 the life is hardly affected by the CTE misfit ratio [5]. The EBPVD TBC variants showing the highest CTE misfit mismatch demonstrate the longest life. Thus the service life is concluded to be independent of mechanical quantities. No mechanical but chemical causes initiate the failure either. The causes are indeed chemical in nature, but the failure modes are different for YSZ and CeSZ top-coated TBC systems. The key issues are highlighted in Table 1; they should assist to interpret the processes of sample failure. 


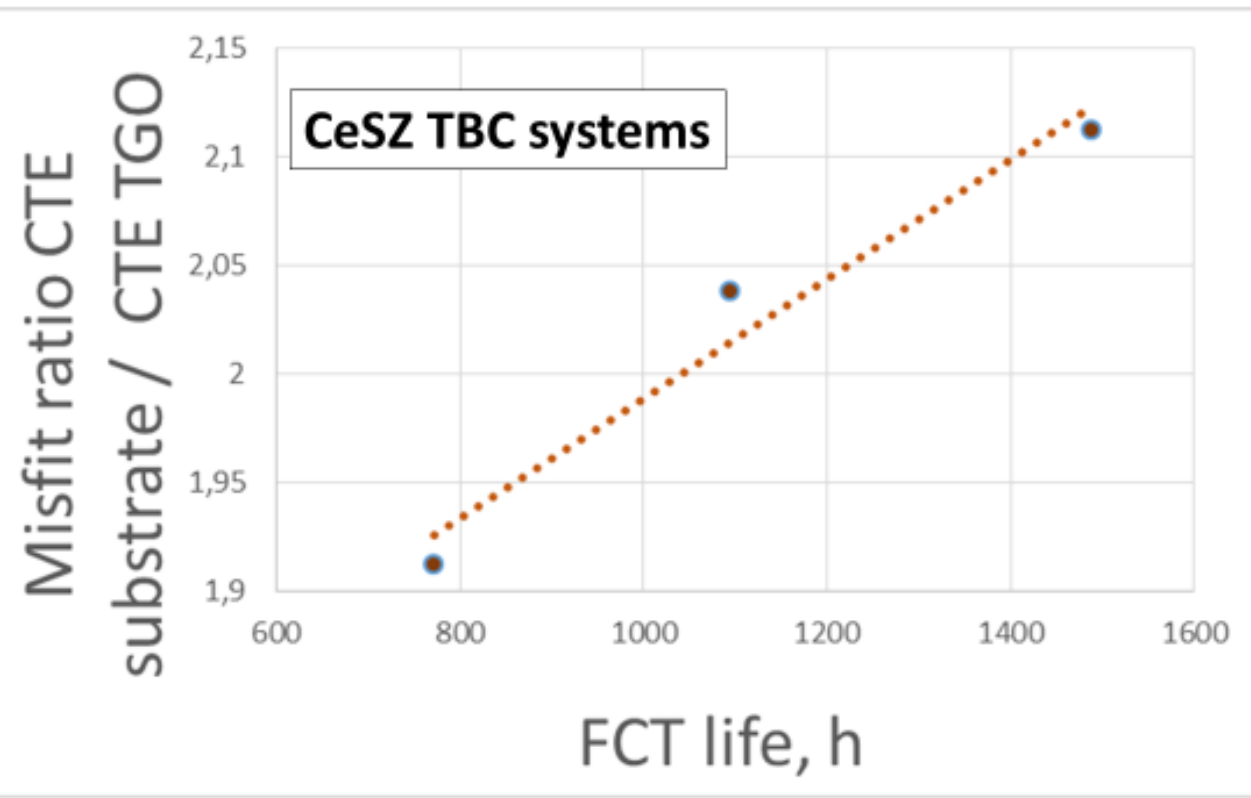

Fig. 1: CTE mismatch ratio versus the average life on three cyclic furnace tested EBPVD TBC systems. Their FCT lives: CMSX-4 (771.7 h), IN100 (1095 h), MCrAlY (1468.7 h). Graph excerpted from data in [5].

Table 1: Highlighting the key issues needed to decode the processes that drive EBPVD TBC system sample failure.

\begin{tabular}{|c|l|c|c|}
\multicolumn{2}{|c|}{ Special features } & \multicolumn{2}{c|}{$\begin{array}{l}\text { Effect of a feature on the lifetime, as well as } \\
\text { location of the separation failure via FCT }\end{array}$} \\
\hline & & $\begin{array}{l}\text { YSZ top-coated } \\
\text { TBC systems }\end{array}$ & $\begin{array}{c}\text { CeSZ top-coated } \\
\text { TBC systems }\end{array}$ \\
\hline 1 & Influence of the CTE mismatch between metal substrate & No effect [4] & No effect \\
\hline 2 & $\begin{array}{l}\text { Influence of the surface smoothness of the substrate prior } \\
\text { to PVD bond coat processing on the service life }\end{array}$ & Decisive [6] & Irrelevant \\
\hline 3 & Site of failure at the end of life & $\begin{array}{c}\text { At Me/TGO } \\
\text { interface }\end{array}$ & $\begin{array}{c}\text { Within the CeSZ } \\
\text { topcoat [3] }\end{array}$ \\
\hline
\end{tabular}

Issue (1) already implies that the adhesion of the EBPVD TBCs cannot be based on a mechanical clamping mechanism, as is to be supposed for PS-generated TBC systems. It indicates the rejection of mechanical influences and constitutes a plea for chemical causes.

Issue (2) highlights the superior surface quality of the substrates to be provided for EBPVD bond coat processing, which is of vital importance for reproducible lifetimes and safe adhesion of YSZ TBC systems. It insinuates heterogeneous nucleation mechanisms for their failure at the Me/TGO interface. - The surface 
quality for CeSZ TBCs, however, is irrelevant since the critical location of failure is no longer at the Me/TGO interface but is within the TBC which has formerly been a strong $t^{\prime}$-stabilized zirconia phase. Life-limiting failure within a formerly strong ceramic also insinuates exclusive chemical causes for disintegration failure.

Issue (3) addresses the exclusive site of failure for YSZ systems. This issue has been discussed and explained in [4]. CeSZ top-coated TBC systems, however, make a difference: they fail at the opposite side of the TGO by cracking within the TBC at the end of life known as "white failure" [3]. - Comparing the failure scenarios between PS- and PVD-generated TBC systems, it can already be concluded in advance: "Traditional" oxidation mechanisms leading to the failure of PS-generated TBC systems, e. g. a critical scale thickness, the stored energy which drives spallation, creep of the alloys and ratcheting effects, are less important in the EBPVD TBC systems of this study.

With regard to the stated principles of relative life and chemical composition of the $\mathrm{MZ}$, the following modus operandi will be brought about. The "life relationships" referring to relative lives at temperature vs. accumulated $\mathrm{Y}+\mathrm{Zr}$ content in the $\mathrm{MZ}$ will be compared to each other with respect to the individual substrates involved. A square root relationship was encountered for the $\mathrm{Y}+\mathrm{Zr}$ content in the $\mathrm{MZ}$ versus the relative lifetime of Ni base YSZ EBPVD TBC systems; yet it could not be interpreted [4]. A similar, but "super-parabolic" relationship between relative life of CeSZ top-coated TBC systems on same Ni-base substrates and the accumulated $\mathrm{Ce}+\mathrm{Y}+\mathrm{Zr}$ content in the MZ has been reported [5]. This previous work and in particular the disparity in the accumulation rates of elements in the $\mathrm{MZ}$ are used in the following to evaluate the mechanisms which rule both the accumulation kinetics and failure modes of Ni-base alloys on the life of EBPVD TBC systems. The discussion of the "substrate effect" will take into account the thermodynamics of point defects in the scale of TBC systems.

\section{Experimental}

\subsection{Materials}

Substrates: Four Ni alloys listed in Table 2 have been taken as substrates for the application of thermal barrier coating systems and subsequent FCT subjection for lifetime evaluation. Routinely the three former alloys CMSX-4, IN100 and MCrAIY were cylindrical samples $\left(\varnothing 6 \times 60 \mathrm{~mm}^{2}\right)$ exhibiting a standard mechanical surface finish of $R_{a}$ 0.15. In parallel single disk-shaped samples $\left(\varnothing 15 \times 1 \mathrm{~mm}^{2}\right)$ per coating type of the three alloys were provided for SEM/EDS analytical purposes [5].

A few cylindrical samples of the IN100 alloy received a non-standard exceptionally smooth surface finish by centerless grinding of about $R_{a} 0.006$. 
The $4^{\text {th }}$ alloy is a ternary Ni-Cr-Al eutectic with no dopants [7]. It is a Bridgman-processed rod showing a directionally aligned lamellar phase structure of $\gamma-\mathrm{Ni}, \beta-\mathrm{NiAl}$ and $\alpha-\mathrm{Cr}$. It represents a no-bond coat model substrate for an YSZ top-coated TBC system. Unlike the routine sample shape of the three alloys mentioned, they are disk-shaped $\left(\varnothing 10 \times 1 \mathrm{~mm}^{2}\right)$. They were manufactured by wire spark erosion from a rod as illustrated in Fig. 2. They thus showed preferred longitudinal or transverse orientation of the texture on the surfaces.

The NiCrAl alloy was manufactured of high purity elemental Al rods, Ni pellets and $\mathrm{Cr}$ flakes via induction melting in a corundum crucible. An extensive sub-step of melting was carried out under hydrogen atmosphere to provide selective removal of sulfur. The subsequent controlled directional solidification during Bridgman processing caused a favorable segregation of residual impurities analogous to a zone melting procedure for purification. Although the remaining traces of impurities have not been analyzed, the procedures taken are considered sufficient to exclude their influence on the adhesion of scales.

\section{Bridgman-type directionally solidified fibrous $\mathrm{Ni}-\mathrm{Cr}$-Al eutectic rod}

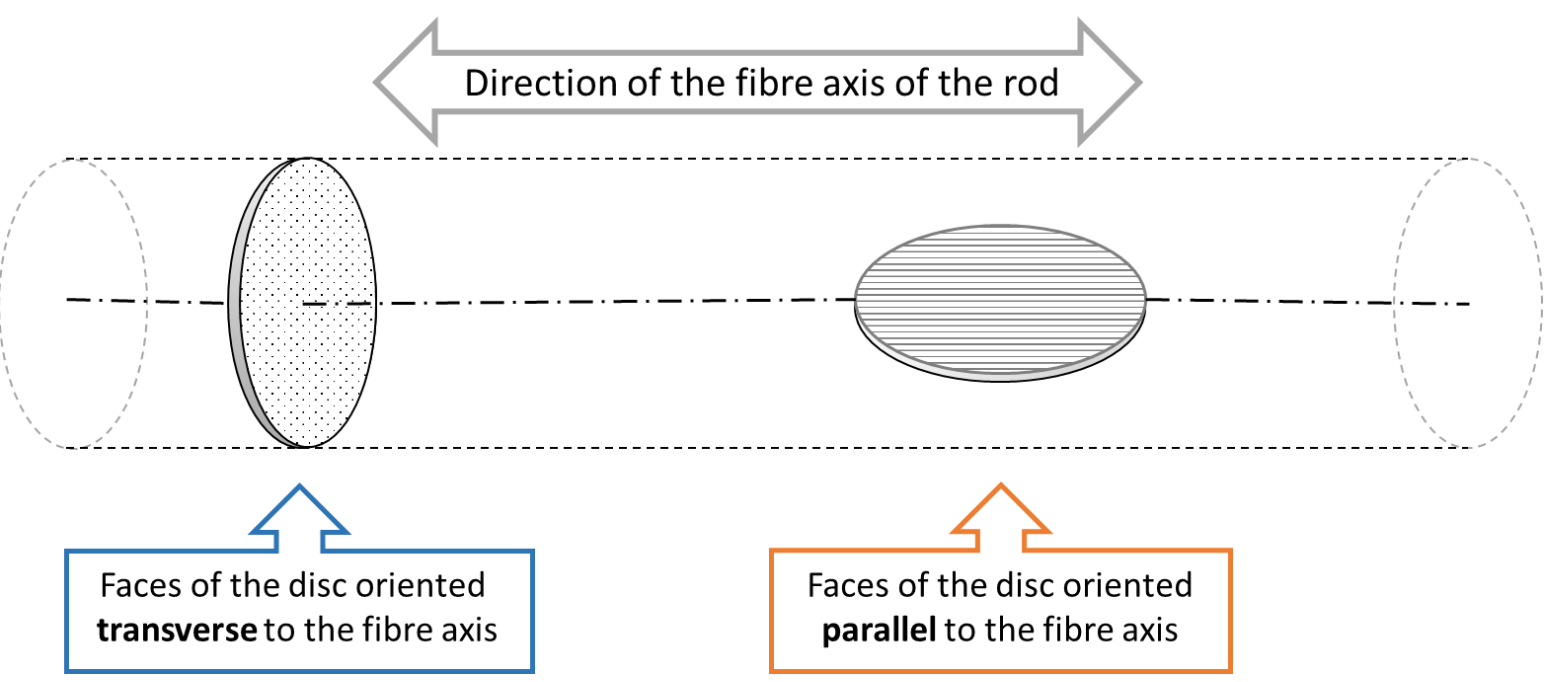

Fig. 2: Schematic representation of two types of disk-shaped samples showing preferred longitudinal or transverse orientation of the texture on the surfaces. The dotted lines indicate the initial shape of the rod from which the samples have been worked by wire spark erosion.

Coatings: All cylindrical and disk-shaped samples of the alloys CMSX-4, IN100 and MCrAlY got 100 $\mu$ m thick standard EBPVD NiCoCrAlY bond coats (nominal composition in wt.\%: Ni-21Co-19Cr-12.5Al-0.15Y). They were then EBPVD top-coated with zirconia base layers. A portion of these topcoats were common YSZ coatings (nominally $\mathrm{ZrO}_{2}-7$ wt.\% $\mathrm{Y}_{2} \mathrm{O}_{3}$ ) deposited by single source processing; the other portion got a CeSZ coating (nominally $\mathrm{ZrO}_{2}-25 \mathrm{CeO}_{2}-2.5 \mathrm{Y}_{2} \mathrm{O}_{3}$ in wt.\%) deposited by dual-source jumping beam evaporation. The sample temperatures were set to $1000^{\circ} \mathrm{C}$ in both cases. - Plasma sprayed bond coatings have been systematically excluded from the experiments in this study.

The disc-shaped samples of $4^{\text {th }}$ alloy of un-doped Ni-Cr-Al got no coatings. 
Table 2: Composition of the alloys for substrates given in wt.\% ( $\mathrm{Ni}$ is balance). The refractory element content of the alloys has been highlighted one by one for Mo, Re, Ta and W; it is given in wt.\%. The total refractory element content is presented jointly in the column at the very right and is given in at.\%.

\begin{tabular}{|c|c|c|c|c|c|c|c|c|c|}
\hline \multirow[b]{2}{*}{ Alloy } & \multirow[b]{2}{*}{ Co } & \multirow[b]{2}{*}{$\mathrm{Cr}$} & \multirow[b]{2}{*}{ Al } & \multicolumn{4}{|c|}{ Refractory elements, wt.\% } & \multirow[b]{2}{*}{ Others } & \multirow{2}{*}{$\begin{array}{c}\begin{array}{c}\text { Refractory } \\
\text { elements }\end{array} \\
\begin{array}{c}\text { Total in } \\
\text { at.\% }\end{array}\end{array}$} \\
\hline & & & & Mo & $\operatorname{Re}$ & Ta & W & & \\
\hline CMSX-4 & 9 & 6.5 & 5.6 & 0.6 & 3 & 6.5 & 6 & $1 \mathrm{Ti} ; 0.1 \mathrm{Hf}$ & 5.5 \\
\hline IN100 & 14 & 9 & 5 & 2.3 & & & & $\begin{array}{c}0.18 \mathrm{C} ; 0.015 \mathrm{~B} \\
1 \mathrm{~V} ; 0.05 \mathrm{Zr}\end{array}$ & 1.3 \\
\hline MCrAIY & 22.2 & 19.8 & 12.2 & & & & & $0.35 Y$ & 0 \\
\hline $\mathrm{NiCrAl}$ & & 37.5 & 7 & & & & & & 0 \\
\hline
\end{tabular}

The concentration of minor additions of $\mathrm{B}, \mathrm{C}$ and other elements are taken from the nominal compositions of the manufacturers of the alloys.

\subsection{Testing}

Isothermal testing: The $4^{\text {th }}$ alloy is a directionally solidified $\mathrm{Ni}-\mathrm{Cr}$-Al eutectic having a strongly anisotropic structure. The oxidation kinetics of the uncoated material were recorded at $1100^{\circ} \mathrm{C}$ parallel and transverse to the fiber orientation (see Fig. 3). The oxidation-induced increase in weight at the edges of the disk samples, which do not have a uniform orientation of the fibers on the surface, is included in the overall weight gain. These cover $1 / 6^{\text {th }}$ of the total area; the resulting uncertainty of the results is considered tolerable in order to detect striking differences in the oxidation behavior parallel and transverse to the fiber orientation.

FCT (cyclic furnace testing): The lifetime of the YSZ and CeSZ system variants was determined by means of the cylindrical samples which have been prepared in an identical manner on the lathe by FCT (cyclic furnace testing). Typical FCT intervals are $50 \mathrm{~min}$ at $1100^{\circ} \mathrm{C}$ temperature and $10 \mathrm{~min}$ cool down to RT in agitated air. The life-span was defined by an early state of spallation of the TBC. All lifetime data are compiled in Table 3. The "relative lifetime" data are additionally given there in glossy numbers. Lifetimes are also plotted as a function of the content of refractory elements of the substrate alloys in Fig. 4. - The disk samples - one specimen per TBC system variety - were similarly exposed to 500 and in part 1000 cycles.

\section{Results}

\subsection{Isothermal oxidation testing of $\mathrm{Ni}-\mathrm{Cr}$-Al samples with no dopants}

Weight gain rates of uncoated $\mathrm{Ni}-\mathrm{Cr}$-Al samples on isothermal heat exposure in air at $1100^{\circ} \mathrm{C}$ parallel and transverse to the fiber axis were done. The kinetics of the sample variant transverse to the fiber orientation is approximated by $\Delta \mathrm{m}=\mathrm{m}_{\mathrm{o}}+\sqrt{k_{\mathrm{p}}} \cdot \sqrt{\mathrm{t}}_{\mathrm{t}}[7]$.

$\mathrm{m}_{0}=6.87 \cdot 10^{-6} \mathrm{in} \mathrm{g} \cdot \mathrm{cm}^{2}$,

$k_{\mathrm{p}}=1.174 \cdot 10^{-12} \mathrm{in}^{2} \mathrm{~cm}^{-4} \mathrm{~s}^{-1}$. 


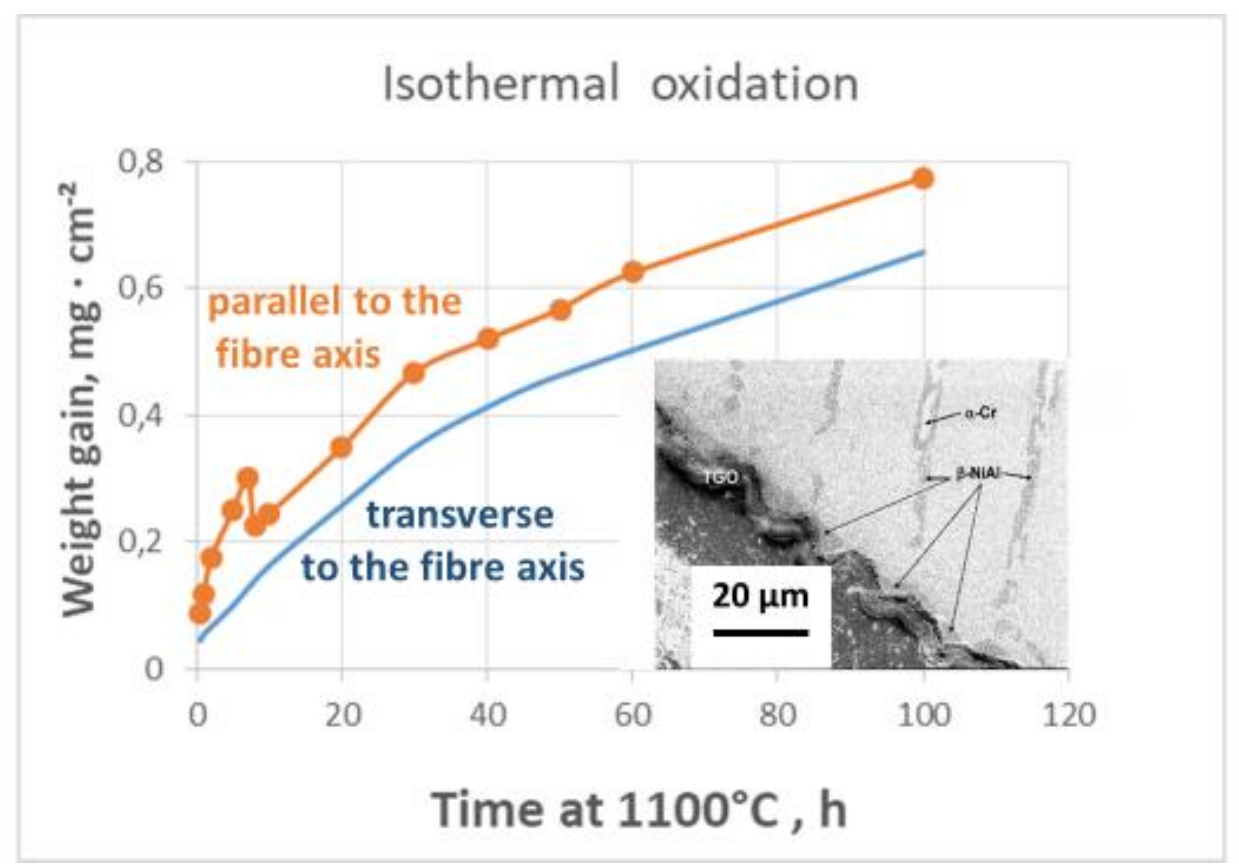

Fig. 3: Weight change of ds eutectic $\mathrm{Ni}-\mathrm{Cr}-\mathrm{Al}$ as a function of time at $1100^{\circ} \mathrm{C}$ in air parallel and transverse to the fiber axis respectively. The inserted micrograph taken from the sample transverse to the fiber axis suggests the formation of a protective continuous TGO cover profile that maintains predominant contact with the $\beta$-NiAl phase.

The weight gain of the sample oxidized parallel to the fiber axis was not protective and resulted in an early spallation event after about eight hours at $1100^{\circ} \mathrm{C}$. Obviously, a tiny fragment (not found) was chipped off from the TGO of the oxidizing sample, which was positioned on a pedestal in the thermo-balance. In contrast, the scale growth on the sample oriented transverse to the lamellar fiber axis was protective as suggested by the graph and image in Fig. 3; it approached regular parabolic oxidation kinetics within a few hours. No spallation was observed after cool-down. This type of structure alignment is considered to be a reliable bond coat surrogate that confirms the probable formation of a stable $\alpha$-alumina sub-layer in a TBC system. - As reported in a previous paper some of the disk-shaped Ni-Cr-Al samples exhibiting this specific structural orientation (transverse to the fibre axis) were coated with YSZ and subjected to FCT [4].

\subsection{Cyclic furnace testing of TBC systems}

The lifetimes at $1100^{\circ} \mathrm{C}$ of the standard processed TBC systems [5] are shown in Fig. 4. They are shown in dependence of the refractory element content in at.\% of the substrates specified in Table 2 . The untraditional representation of the lifetime vs. refractory element content of the substrates already takes up the working hypothesis of this study, which aims for clarifying the relationship between decreasing lifetimes and increasing content of refractory elements.

The particular samples of the IN100 alloy having a non-standard exceptionally smooth surface resulted in about twice the life as compared to standard processed IN100 samples (1185 h compared to $550 \mathrm{~h}$ ). They are not included in Fig. 4. 


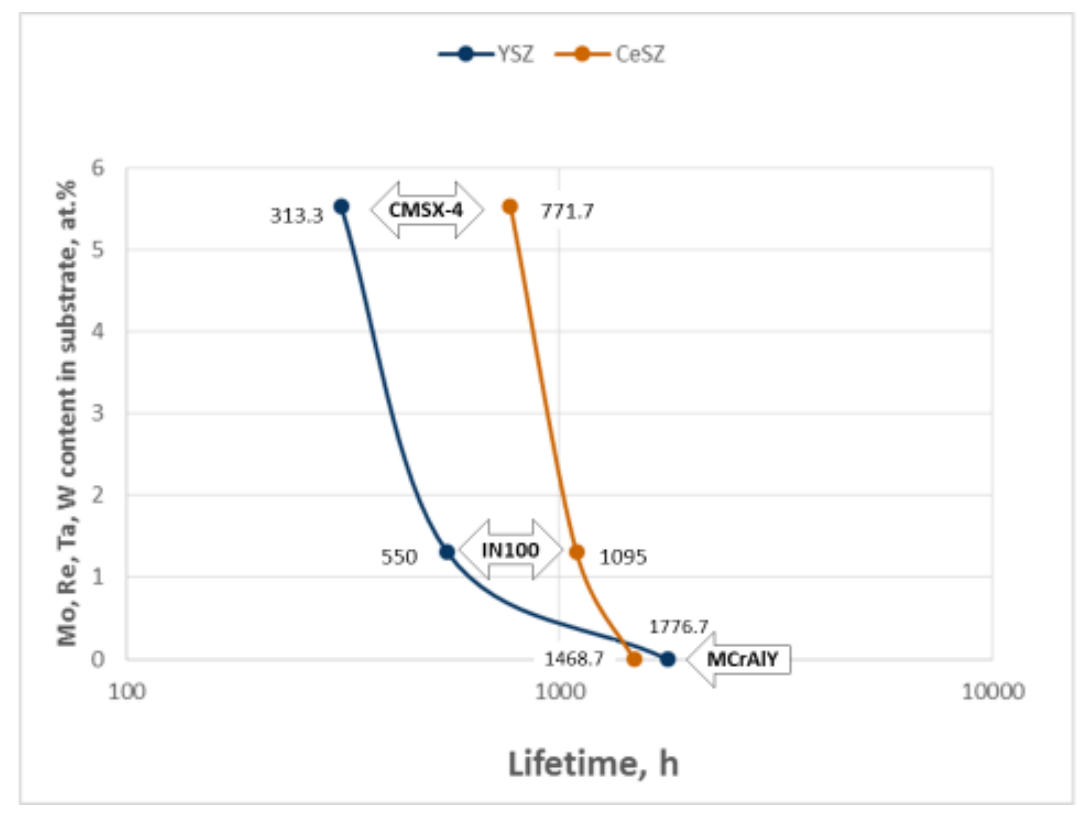

Fig. 4: Lifetimes at $1100^{\circ} \mathrm{C}$ vs. total refractory element content (Mo, Re, Ta, and $\mathrm{W}$ in at.\%) in the substrate alloys of Ni-base TBC systems with YSZ and CeSZ topcoats.

\subsection{SEM/EDS data of the mixed zone}

The MZ of the disk-shaped TBC samples being FCT subjected for 417 hours (500 cycles) at $1100^{\circ} \mathrm{C}$, and additionally two extra tested samples the same for one hour (NiCrAI/YSZ) [4] or 835 hours (MCrAIY/NiCoCrAIY/CeSZ) [5], has been analyzed by SEM/EDS. All samples formed a TGO by FCT; and all samples showed a MZ of up to about $1.5 \mu \mathrm{m}$ thickness on the upper periphery of the TGO. The EDS data of the $\mathrm{MZ}$ are given in Table 3. They are representative for one sample per coating type and refer to the analysis at up to ten different locations along the centerline of the mixed zone.

Table 3: FCT times at temperature (hot hours at $1100^{\circ} \mathrm{C}$ ), related relative lifetimes of the analyzed samples (bold numbers) and EDS data of the MZ (at.\%, balance is $\mathrm{Al}$ and $\mathrm{O}$ ).

\begin{tabular}{|c|c|c|c|c|c|c|c|}
\hline TBC system & $\begin{array}{c}\text { Hot hours / } \\
\text { Relative } \\
\text { lifetime }\end{array}$ & $\mathrm{Cr}$ & $\mathbf{Y}$ & $\mathrm{Zr}$ & $\mathrm{Ce}$ & $\begin{array}{c}\text { Other } \\
\text { elements }\end{array}$ & Ref \\
\hline \multicolumn{8}{|l|}{$\begin{array}{c}\text { Without } \\
\text { bond coat }\end{array}$} \\
\hline Ni-Cr-Al / YSZ & $\begin{array}{l}1 \\
2\end{array}$ & 20.0 & 0.78 & 4.32 & & $0.7 \mathrm{Ni}$ & [4] \\
\hline \multicolumn{8}{|l|}{ Bond-coated } \\
\hline $\begin{array}{c}\text { IN100 / } \\
\text { NiCoCrAlY / YSZ }\end{array}$ & $\begin{array}{c}417 \\
0.758\end{array}$ & $\begin{array}{r}0.45 \\
\pm 0.04 \\
\end{array}$ & $\begin{array}{r}1.58 \\
\pm 0.47 \\
\end{array}$ & $\begin{array}{r}1.49 \\
\pm 0.61 \\
\end{array}$ & & $\begin{array}{l}\leq 0.2 \mathrm{Co} \\
\leq 0.15 \mathrm{~V}\end{array}$ & [4] \\
\hline CMSX-4 / & 417 & 0.22 & 1.64 & 2.58 & & & {$[4]$} \\
\hline
\end{tabular}




\begin{tabular}{|c|c|c|c|c|c|c|}
\hline NiCoCrAIY / YSZ & 1.33 & \pm 0.09 & \pm 0.45 & \pm 0.42 & & \\
\hline $\begin{array}{c}\text { MCrAlY / } \\
\text { NiCoCrAIY / YSZ }\end{array}$ & $\begin{array}{c}417 \\
0.235\end{array}$ & $\begin{array}{r}0.21 \\
\pm 0.10\end{array}$ & $\begin{array}{r}0.96 \\
+0.38\end{array}$ & $\begin{array}{r}0.84 \\
+0.33\end{array}$ & & [4] \\
\hline $\begin{array}{c}\text { IN100 / } \\
\text { NiCoCrAIY / CeSZ }\end{array}$ & $\begin{array}{c}417 \\
0.38\end{array}$ & $\begin{array}{r}0.42 \\
\pm 0.11 \\
\end{array}$ & $\begin{array}{r}0.85 \\
\pm 0.08 \\
\end{array}$ & $\begin{array}{r}0.76 \\
\pm 0.25 \\
\end{array}$ & $\begin{array}{c}1.00 \\
\pm 0.04\end{array}$ & [5] \\
\hline $\begin{array}{c}\text { CMSX-4 / } \\
\text { NiCoCrAlY / CeSZ }\end{array}$ & $\begin{array}{c}417 \\
0.54\end{array}$ & $\begin{array}{l}0.16 \\
\pm 0.01\end{array}$ & $\begin{array}{r}0.70 \\
\pm 0.11\end{array}$ & $\begin{array}{l}1.16 \\
\pm 0.13\end{array}$ & $\begin{array}{r}1.56 \\
\pm 0.11\end{array}$ & [5] \\
\hline $\begin{array}{c}\text { MCrAlY / } \\
\text { NiCoCrAlY / CeSZ }\end{array}$ & $\begin{array}{c}417 \\
0.28\end{array}$ & $\begin{array}{r}0.32 \\
\pm 0.15\end{array}$ & $\begin{array}{l}0.79 \\
\pm 0.25\end{array}$ & $\begin{array}{r}0.53 \\
\pm 0.01\end{array}$ & $\begin{array}{l}1.00 \\
\pm 0.22\end{array}$ & [5] \\
\hline $\begin{array}{c}\text { MCrAlY / } \\
\text { NiCoCrAlY / CeSZ }\end{array}$ & $\begin{array}{c}835 \\
0.56\end{array}$ & $\begin{array}{l}0.41 \\
\pm 0.16\end{array}$ & $\begin{array}{l}1.57 \\
\pm 0.33\end{array}$ & $\begin{array}{l}0.70 \\
\pm 0.21\end{array}$ & $\begin{array}{l}1.22 \\
\pm 0.91\end{array}$ & [5] \\
\hline
\end{tabular}

\subsection{The relative lifetime of YSZ and CeSZ top-coated systems}

In order to compare the obtained EDS data of the different samples more easily, the "relative lifetime" has been introduced as a useful reference tool for the following discussion. In the following life is to distinguish between the actual (= average lifetime of a coating type) and relative life. As already mentioned [4] the relative life of 1 is the portion of $100 \%$ of the average lifespan of a representative number of identical samples; it corresponds to a collective content of $\mathrm{Y}+\mathrm{Zr}$ in the $\mathrm{MZ}$ of 3.7 at.\% for $\mathrm{YSZ}$ systems. - The relative life of EBPVD CeSZ TBC systems corresponds to a higher REE $+\mathrm{Zr}$ collective content of $\mathrm{Ce}+\mathrm{Y}+\mathrm{Zr}$ of 5.0 at.\% in the MZ [5]. So the concentrations of REEs + Zr in the MZ of YSZ and CeSZ TBC systems of 3.7 and 5.0 at.\% represent lifetime criteria. The partial relative lifetimes of both TBC systems in dependence of the REE $+\mathrm{Zr}$ content in the $\mathrm{MZ}$ can be derived from the graph in Fig. 5.

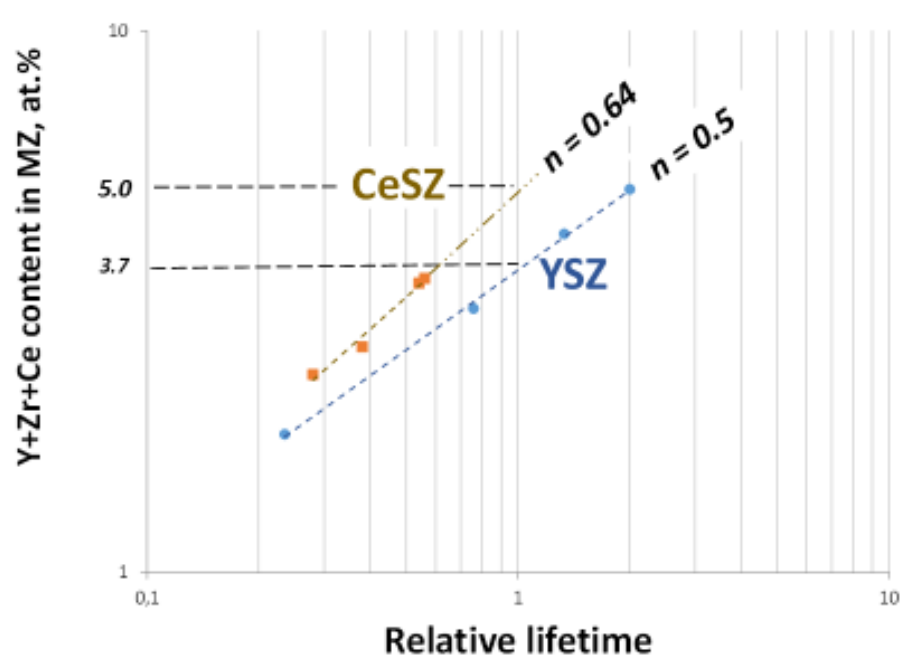

Fig. 5: $Y+Z r+C e$ content (at.\%) in the MZ vs. relative lifetime of $Y S Z$ and CeSZ top-coated TBC systems in log-log format $[4,5]$. 
The "uniform lifetime relationships" in Fig. 5 show the enrichment of the rare earth elements and Zr in the MZ of a TBC sample given in Table 3 over the relative life at high temperatures. They represent the early, intermediate and late stages of life of CeSZ and YSZ topcoated systems. The data for YSZ TBCs encompass YSZ TBC systems with NiCoCrAlY bondcoats as well as a no-bondcoat system free of reactive alloying elements as already said [4].

\section{Discussion}

\subsection{FCT failure mechanisms in YSZ and CeSZ systems}

Fractographic analysis has shown that the locations of FCT failure in $\mathrm{YSZ}\left(\mathrm{ZrO}_{2}-7 \mathrm{Y}_{2} \mathrm{O}_{3}\right.$ in wt.\%) and $\mathrm{CeSZ}\left(\mathrm{ZrO}_{2}-\right.$ $25 \mathrm{CeO}_{2}-2.5 \mathrm{Y}_{2} \mathrm{O}_{3}$ in wt.\%) top-coated TBC systems are different [5]. Accordingly, the mechanisms of adhesion alias cohesion are different for both systems either. So as anticipated the different mechanisms of failure are discussed separately for YSZ and CeSZ type systems.

\subsubsection{YSZ systems}

Surface finishing of the substrates of YSZ systems is of vital importance for realizing reproducible lifetimes. This statement had been checked on identical TBC samples of an IN100 alloy which have been mechanically finished differently: they have had a standard finish whereas some of them an extremely smooth surface finish. The last variants reached about twice the TBC life compared to the standard life. They achieved equal times, irrespective of whether the substrates had been surface treated by centerless grinding or by a 4000 grit finish [6]. A counterexample for surface finishing of the substrates reports that a particularly rough finish has been produced by grit blasting, which resulted in much shorter lifetimes [8]. Obviously the prior mechanical treatment of the substrate surface preconditions the flatness of the follow-on Me/TGO interface. Hence subsequent heterogeneous nucleation of pores or voids is assumed to be promoted by vacancy agglomeration at tips and ridges at the interface, and that the more the rougher the interface. The energetic argument implies: The smaller the radius $r$ of a tip or edge, which is sticking out from the metal border, the higher the stress on a nucleated pore at this site. The stress on a pore corresponds to the partial pressure for oxygen $\Delta p_{02}$ in this cavity which is inversely related to the radius $r$ of curvature at interface roughness according to

$$
\Delta p_{\mathrm{O} 2} \sim 1 / \mathrm{r} \text {. }
$$

The pores and voids at these irregularities compromise the adhesion strength; they will initiate blistering as also concluded by direct evidence or TEM investigation studies of fracture surfaces, which were created by void induced separation failure of former Me/TGO interfaces [9]. The increasing pressure according to $\Delta p_{\mathrm{O} 2}$ as initial failure-relevant working hypothesis is confirmed by the following experimental findings (quote): "A few of the facets (inner planes within the pores) contained an oxide scale" [10].

For this reason the $p_{02}$ at the metal/scale interface turns out to be a failure-critical issue of YSZ systems. In this regard, the rate-limiting sub-step of the oxidation occurring at this interface is discussed by usage of point defect concentrations in the $\alpha$-alumina scale. The sub-step in Vink notation for vacancy migration of point defects in the semiconducting Schottky-type alumina lattice is 


$$
\mathrm{O}_{\mathrm{O}}^{\mathrm{x}}+2 / 3 V_{\AA \mathrm{Al}}^{\cdots}+2 \mathrm{~h} \cdot->1 / 2 \mathrm{O}_{2}
$$

The reaction constant $K^{*}$ indicating concentrations, molar proportions or chemical activities of point defects at related temperatures in square brackets is

$$
K^{*}=p_{\mathrm{O}_{2}}^{1 / 2} /\left(\left[V_{\mathrm{Al}}^{\cdots}\right]^{2 / 3} \cdot[\mathrm{h} \cdot]^{2} \cdot\left[O_{\mathrm{O}}^{\mathrm{x}}\right]\right)
$$

With regard to $K^{*}$ a deeper $p_{\mathrm{O}_{2}}$ regime of Al-rich and REE doped substrates underneath the TGO results in some lower concentration of Al vacancies (and electron holes $\mathrm{h}$ ) aside from countercurrent oxygen $O^{\mathrm{x}}{ }_{\mathrm{o}}$. The oxygen pressure dependency of the point defect concentration of $\mathrm{V}_{\mathrm{Al}}{ }^{\prime \prime}$ 'and $(\mathrm{h} \cdot)$ refers to the major part of point defects in three-charged cation oxides [11], which is in the particular $p_{\mathrm{O}_{2}}$ range

$$
\partial \log \left[V_{\grave{A l}}^{\cdots}\right] / \partial \log p_{\mathrm{O}_{2}}=3 / 16
$$

Safe adhesion of the scale at the metal/scale interface of $\mathrm{Ni}$ base alumina formers requires a decisive $p_{\mathrm{O}_{2}}$ range: the $p_{\mathrm{O}_{2}}$ at this interface must stay below the dissociation pressure of $\mathrm{Al}_{2} \mathrm{O}_{3}$; the dissociation pressure is not a fixed value at temperature but decisively depends on the chemical activity of Al. In the actual case of Ni alloys it is lower since $\mathrm{Al}$ is dissolved in the alloy. In the $\gamma$-Ni phase it is $\leq 10^{-26} \mathrm{~atm}$ at $1100^{\circ} \mathrm{C}$ [12]. It is about $\leq 10^{-27}$ atm at $1100^{\circ} \mathrm{C}$ on $\beta-\mathrm{NiAl}$ phase. On the basis of a $\gamma / \beta$ phase microstructure, the adhesion of a TGO on a $\beta$-phase has proved superior to that on the $\gamma$-phase that have been jointly subjected to same oxygen potentials and temperatures. While the adhesion of the $\beta$-NiAl / TGO interphase boundary already exceeded the tensile strength of the $\beta$-NiAl matrix, the bonding of the $\gamma$-Ni / TGO interface instead suffered from escalating separation. E. g. a TGO on an appropriate $\gamma / \beta$ structure is shown in Figure 3 after isothermal oxidation; the superior scale adhesion on the $\beta$ phase on this $\gamma / \beta$ structure has been disclosed via FCT procedures [4].

An added downward shift of $p_{\mathrm{O}_{2}}$ is caused by doping alumina formers with REEs like $\mathrm{Y}$ and trivalent lanthanides. In the very bottom of the TGO, the extra formation of a continuous interstitial garnet phases, e. g. the YAG phase $\mathrm{Y}_{3} \mathrm{Al}_{5} \mathrm{O}_{12}$, cannot be ruled out. The effectiveness of a YAG monolayer on lowering the $p_{\mathrm{O} 2}$ potential at the Me/TGO interface is also hypothesized. This hypothesis is indirectly supported by experiments on Y-doped FeCrAl alloys. They form a wavy Me / TGO interface during isothermal oxidation for $100 \mathrm{~h}$ at $1200^{\circ} \mathrm{C}$. In the oxide pockets along the interface, SEM cross sections show Y / Al mixed oxides as also evidenced by XRD patterns. These alloys are mainly YAG $\left(\mathrm{Y}_{3} \mathrm{Al}_{5} \mathrm{O}_{12}\right)$ and a smaller fraction of YAP $\left(\mathrm{YAIO}_{3}\right)$ [13]. The YAG and YAP phases, in conjunction with the ferritic substrate, form a ternary equilibrium. This fact precludes the inclusion of $\mathrm{Al}_{2} \mathrm{O}_{3}$ at the Me/TGO interface according to the Gibbs ' phase rule. Alumina is excluded from contact with the metal phase. This statement and the temperature-independent stability of the YAP phase have been confirmed [14]. The most likely phase sequence of TGOs in TBCs having Y-doped alumina-forming alloy substrates, which forms at service temperatures, would be: Me substrate / $\mathrm{YAG} / \mathrm{Al}_{2} \mathrm{O}_{3} /$ mixed Al-Zr oxide zone.

The Y/Al oxides alias YAG interfaces cause a lower $p_{\mathrm{O} 2}$ of about $10^{-28}$ atm at $1100^{\circ} \mathrm{C}$ at the TGO growth front as has been experienced on a Y-doped Ni alloy [15]. - As generally recognized the concentration of cation point defects is representing the diffusivity of matter for a given oxygen potential gradient; hence - in the given example at $1100^{\circ} \mathrm{C}$ for the $p_{\mathrm{O}_{2}}$ range of at least between $10^{-26}$ to $10^{-28} \mathrm{~atm}$ - it is directly related to actual experimental oxidation rates from selected test series as shown in Fig. 6. 


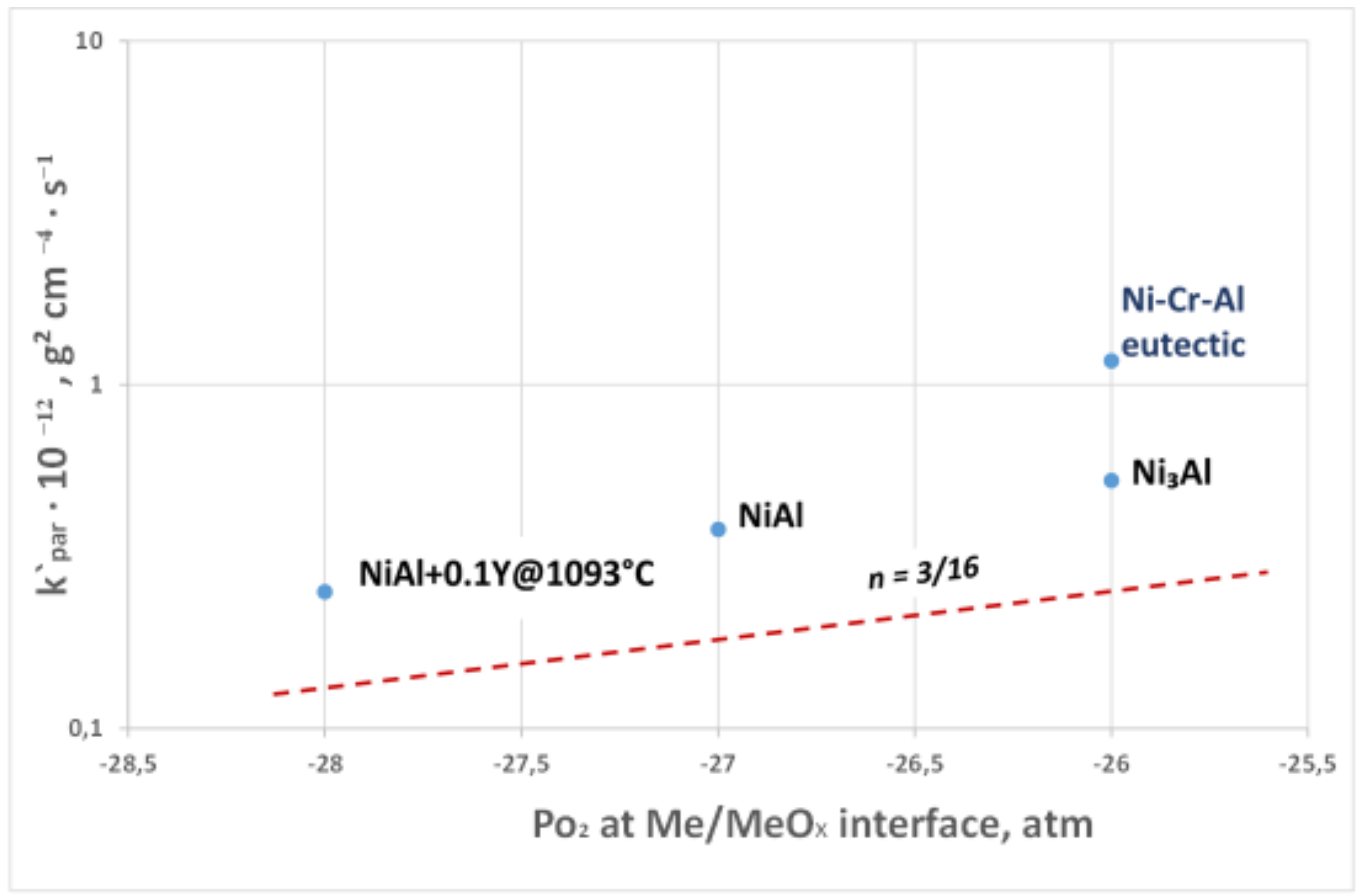

Fig. 6: Schematic of the oxygen pressure dependency on "optimal" experimental parabolic oxidation rate constants of alumina forming alloys at $1100^{\circ} \mathrm{C}$. Rate constants are given for "binary" $\mathrm{Ni}_{3} \mathrm{Al}$ [16], $\mathrm{NiAl}$ [17], NiAl+0.1Y at $1093^{\circ} \mathrm{C}$ [18], which each refer to a $p_{\mathrm{O}_{2}}$ according [12], [12] and [15]. Due to its low Al content, the ternary NiCrAl eutectic $\mathrm{Ni}_{49} \mathrm{Cr}_{37.5} \mathrm{Al}_{13.5}$ has been approximated to the $p_{\mathrm{O}_{2}}$ of the $\mathrm{Ni}_{3} \mathrm{Al}$ [this study].

The effect of doping with rare earth elements is reported to lower oxidation rates corresponding to a factor of 2 to 4 [19]. A comparable decline in oxidation rate is also suggested in the diagram in Fig. 6 highlighting experimental data of binary Ni-Al compositions of $\gamma$ and $\beta$ phase and the effect of an optimal $\mathrm{Y}$ dopant content on it. - The oxidation rates of the ternary DS eutectic Ni-Cr-Al alloy, however, are obviously raised compared to the binary $\mathrm{Ni}$-Al alloys which is supposed to result from additional alloying with $\mathrm{Cr}$. The point defect concentration as a representative for diffusion velocities is assumed to remain in the same order of magnitude due to the presence of equivalent $\mathrm{Cr}$ ions in Al lattice positions of the TGO. Under this premise the diffusion rates cannot dramatically be risen. Hence the raised scale growth rate is supposed to be mainly due to the higher dynamic participation of $\mathrm{Cr}$ in cation transport as is also suggested by the low activation energy for $\mathrm{Cr}^{3+}$ tracer diffusion in $\alpha$-alumina of $265 \mathrm{kJmol}^{-1}$ [20] compared to a $\square 100 \mathrm{~kJ} \cdot \mathrm{mol}^{-1}$ higher value for $\mathrm{Al}^{3+}$ selfdiffusion in $\alpha-\mathrm{Al}_{2} \mathrm{O}_{3}$. So the difference in cation mobility of $\mathrm{Al}^{3+}$ and $\mathrm{Cr}^{3+}$ in $\alpha-\mathrm{Al}_{2} \mathrm{O}_{3}$ accounts for the $\mathrm{Cr}$ effect.

The transport of matter to the $\mathrm{MZ}$ is based on the mass flux from the YSZ topcoat and supply of $\mathrm{Y}$ from the metallic $Y$ reservoir of the bond coat.

It should be mentioned in parenthesis that the reservoir of $Y$ in the metal at the Me/scale interface of this study is fixed by the standard bond coat having constant thickness and composition. The substrate and its 
thickness, however, may contribute to the entire $Y$ reservoir, depending on the $Y$ content of the substrate and its thickness. This question has been dealt with in detail with regard to an optimum reactive element content for the oxidation rate and the lifetime considering the contents of such elements and the thicknesses of the bond coats and substrates [21]. Without intending to investigate this fact in the context of this study, the comparatively long average lifetime of the YSZ top-coated MCrAIY samples is noticeable. Obviously, the common reservoir of $\mathrm{Y}$ in the substrate $(0.35 \mathrm{wt} \% \mathrm{Y})$ and in the bond coat $(0.15 \mathrm{wt} \% \mathrm{Y})$ plays an important role in terms of lifetime. It should be noted in advance in this chapter with regard to the following chapter on CeSZ system types that the implied life-prolonging influence of the MCrAIY substrate in YSZ systems is not observed in CeSZ systems. This appending observation suggests that different failure mechanisms in YSZ (depending on the entire $Y$ content of the $Y$ reservoir) and CeSZ systems (insensitive to the size of the $Y$ reservoir) might be present.

The quantitative ratio of the two mass fluxes from above and below is still discussed with regard to YSZ and CeSZ TBCs in the following. In the late state of TBC life this source for Y supply from below seems to become exhausted. This view is also confirmed by the finding that the lifetime is determined by the consumption of the Al reservoir as a function of the TGO growth rate [22]. This impression refers to the diagram in Fig. 7: it shows a $\mathrm{Y} / \mathrm{Zr} \approx 1$ ratio in the $\mathrm{MZ}$ vs. the relative life. Due to the preferred $\mathrm{Y}$ off-diffusion from below and successive shortage of $Y$ the $Y / Z r$ ratio in the $M Z$ drops to a low value in the late life, which seemingly approximates the $\mathrm{Y} / \mathrm{Zr}$ ratio of the composition of the YSZ topcoat. There is probably a noticeable tendency of the MZ to accumulate $\mathrm{Y}$, which is primarily supported by the driving force of the oxygen potential gradient in the CAZ and the mobility of the cations in the sub-lattice. In the MZ, however, no such potential gradient is present, so that only a diffusive balance between $\mathrm{MZ}$ and TBC is likely to have taken place.

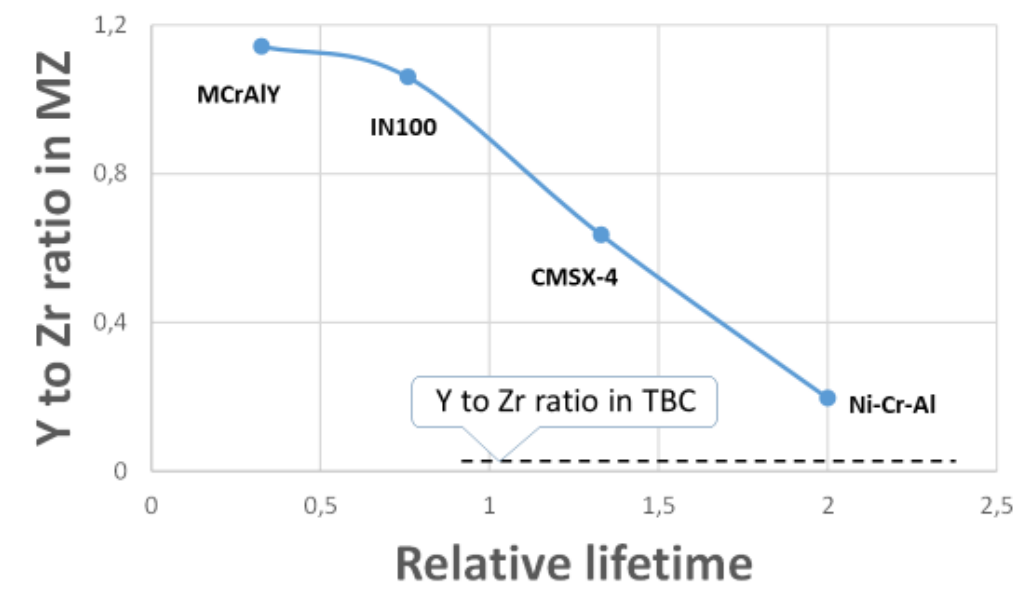


Fig. 7: $\mathrm{Y}$ to $\mathrm{Zr}$ ratio in the $\mathrm{MZ}$ as a function of the relative life (data taken from Table 3). The graph indicates a decrease in the provision of $Y$ from the bond coat reservoir vs. relative life. The $Y$ to $Z r$ ratio of the MZ drops to ratio of the composition of the TBC after the anticipated scale of lifetime.

\subsubsection{CeSZ systems}

The surface finishing of the substrates of CeSZ systems is of minor importance as can be understood because of the fracture failure occurring at the opposite side of the TGO. With regard to a critical $p_{\mathrm{O} 2}$ at the Me/TGO interface for "safe" adhesion as given above, however, it can already be concluded that the oxygen potential at the corresponding interface for the CeSZ TBC systems is settled below the decomposition pressure $p_{\mathrm{O}_{2}}$ of alumina, i.e. in a "safe" pressure range. This fact also explains why the location of the layer failure is not at the $\mathrm{Me} / \mathrm{TGO}$ interface but is located in the CeSZ topcoat and thus at atmospheric pressure. From this fact, the following hypothesis can be deduced: The so-called rare earth effect via doping with $Y$ may not be as crucial for obtaining a long life as this is for YSZ TBC systems.

A brittle fracture mode can be expected to occur at the smooth interface between $\mathrm{MZ}$ and CeSZ topcoat that is initiated there by interfacial shear stresses. This is not observed in this study. Incidentally, it should be noted that the influence of thermal stresses along layer boundaries, so-called mismatch effects, in the present TBCs has never been identified as a lifetime determining cause. Instead the probable area for breakdown in the CeSZ topcoat is just next to the MZ. This zone is exemplarily shown for a FCT subjected IN100/NiCoCrAIY/CeSZ sample in Fig. 8. It is highlighted at high magnification showing a sub- $\mu \mathrm{m}$ flaky microstructure of the MZ. The zirconia top coat no longer exhibits its original structure of a columnar PVD structure, but has been transformed into a contourless structure. However, this aspect should not be further explored here.

In particular the size of the grains in the $M Z$ is smaller by orders of magnitude. A structure like that suggests the chance for an unimpeded mass flow along short-circuit paths via the manifold grain boundaries. Possibly a mass flow like that is not controlled by diffusion but will be ruled by interface reactions. - The determination of the phases involved in the MZ proved too extensive within the frame of the present study. E. g. traces of $\mathrm{Ni}^{2+}$ and $\mathrm{Co}^{2+}$ incorporated in the $\mathrm{MZ}$ by in-diffusion from the metal backside below are reported to give rise to a series of additional chemical compounds [23].

The microstructures of the TGO and the Me /TGO interface do not show grains and pegs of YAG phase any more as otherwise expected to precipitate in the TGO of YSZ TBC systems. Apparently the preformed facetted yttria islands on the smooth surface of the bond coats which commonly form in the course of vacuum annealing on the surface of bond coats before YSZ deposition have disappeared during subsequent deposition processing in the $\mathrm{Ce}$ rich vapor atmosphere. Rather an arrangement of transient aluminas $+\mathrm{Ce}_{2} \mathrm{O}_{3}+\mathrm{CeAlO}_{3}$ phases is assumed to have been formed in this intermediate state of scale formation in order to comply with Gibbs' phase rule: it rather suggests the creation of $\alpha-\mathrm{Al}_{2} \mathrm{O}_{3}+\mathrm{Ce}_{2} \mathrm{O}_{3}+\mathrm{CeAlO}$ phases thus confirming the existence of thermodynamic equilibria between the MZ/CeSZ interface and the phases in the $\mathrm{MZ}$. 


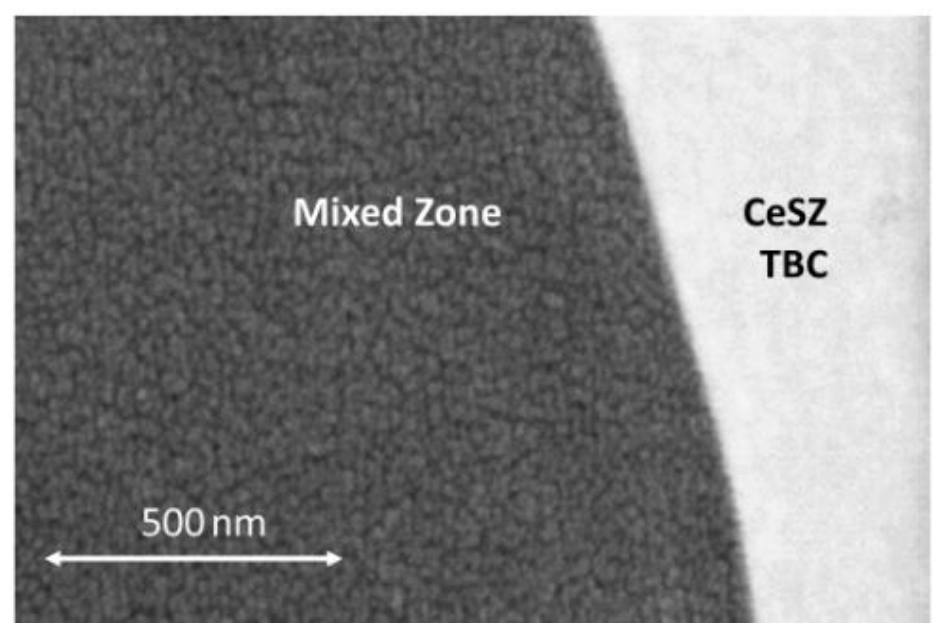

Fig. 8: SEM micrograph of CeSZ TBC cross section on bond-coated IN100 substrate after 500h FCT at $1100^{\circ} \mathrm{C}$ exposing a smooth interface between $\mathrm{MZ}$ and CeSZ topcoat. The $\mathrm{MZ}$ reveals a sub-micron sized equi-axed grain structure. The former columnar TBC has adopted a "monolithic" structure.

The more detailed understanding of the accumulation of $\mathrm{Ce}+\mathrm{Zr}+\mathrm{Y}$ in the $\mathrm{MZ}$ will be shown in a graph in Fig. 9. Both types of systems theoretically have the possibility of effecting the accumulation of these elements in the $\mathrm{MZ}$ both by inflow from the bond coat and from the zirconia-base topcoat. So in particular the $\mathrm{Y}$ content in the MZ of YSZ and CeSZ TBCs has been chosen for comparison purposes, in which the previously discussed ability of $\mathrm{Y}$ to lower the of $p_{\mathrm{O}_{2}}$ in the $\mathrm{Me} / \mathrm{MeO}$ phase equilibria also plays a role. The comparison of the $\mathrm{Y}$ accumulation rates between the two TBC systems in Fig. 9 refer to the same real times of $417 \mathrm{~h}$ (500 cycles) at temperature and for the same $\mathrm{Ni}$-based alloys.

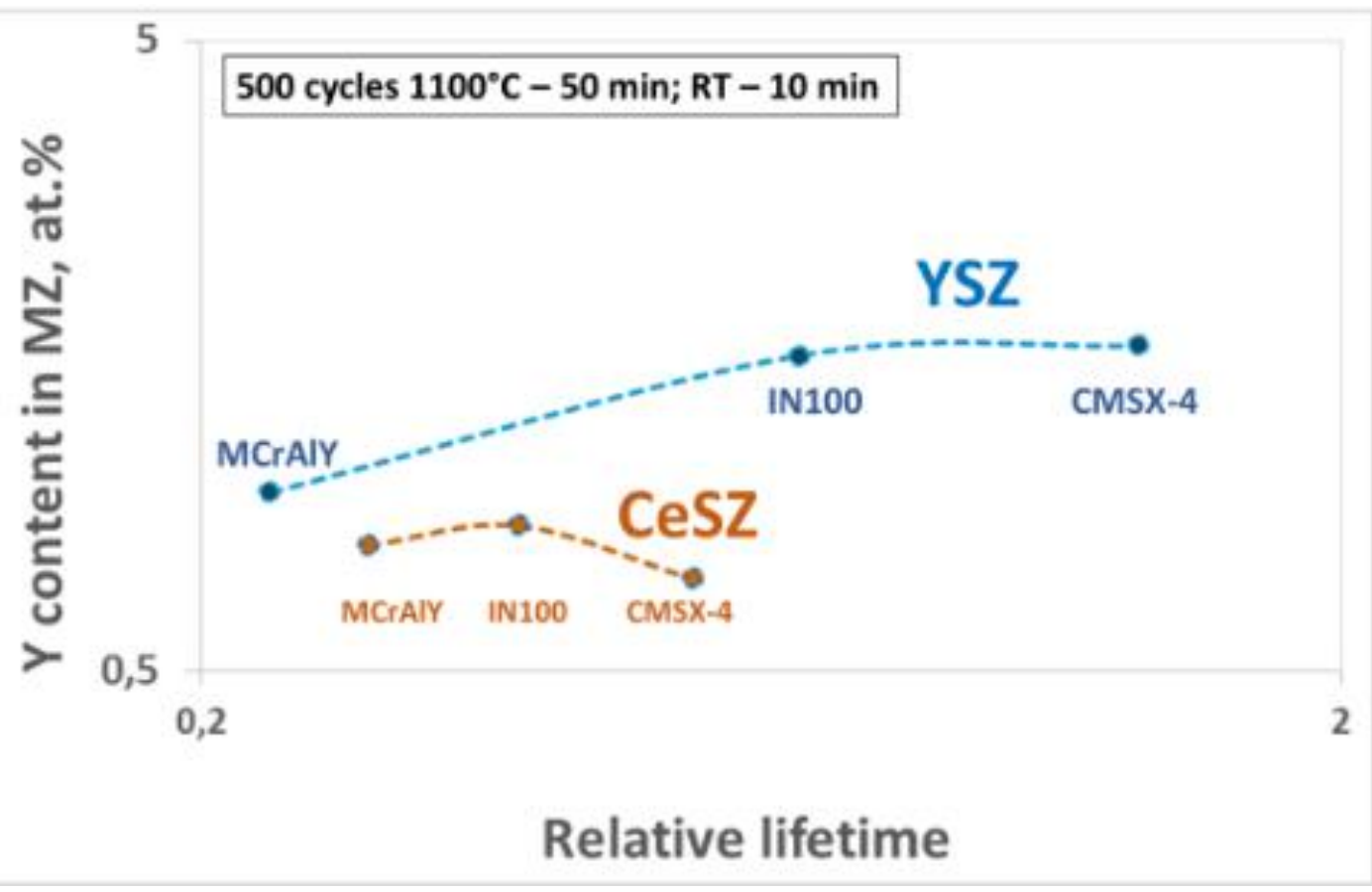


Fig. 9: $Y$ content in the MZ of YSZ and CeSZ TBC systems as a function of the relative life (log-log format) for the data obtained after $417 \mathrm{~h}$ (alias 500 cycles at $1100^{\circ} \mathrm{C}$ ). They show a lower $\mathrm{Y}$ content in the MZ for CeSZ systems compared to YSZ systems if same hot hours at temperature are considered.

This diagram highlights the "low" Y contents (2.5 wt\%) in the MZ for the CeSZ variants and the "high" Y contents (7 wt\%) for the YSZ variants. The CeSZ ones account for a lower supply rate of $Y$ from the metal base reservoir to the MZ through the TGO, where, however, the YSZ variants have a much higher accumulation rate for $Y$ in the MZ. The Y content in the YSZ topcoat is about 3 times as high as in the CeSZ topcoat. However, the gain of high $\mathrm{Y}$ content in the MZ is excluded at the expense of the YSZ top layer since the $\mathrm{Y}$-stabilized phase in the topcoat is not significantly affected.

So the lower diffusion rate is considered to be due to a lower oxygen potential gradient which is the main driving force for the diffusion of $Y$. The hypothesis of lower diffusion rates for $Y$ in CeSZ top-coated systems due to the lower oxygen potential gradient is mentioned here in advance. It is explained and schematically detailed in chapter 4.2 and Fig. 13.

One more aspect of the $\mathrm{Y}$ transport refers to the rate of $\mathrm{Y}$ enrichment in the $\mathrm{MZ}$ compared to a representative element for the diffusion rates of the remaining elements in the MZ. It is given here for some intermediate stage of life, in particular at 28 to $56 \%$ of relative life in Fig. 10.

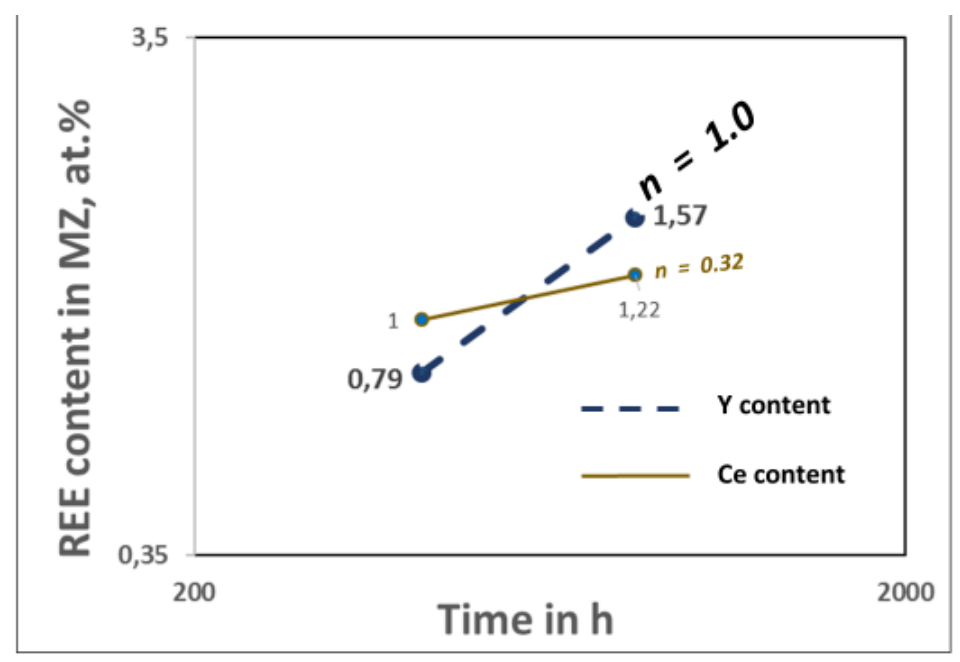

Fig. 10 The REE content for $\mathrm{Y}$ and $\mathrm{Ce}$ in the $\mathrm{MZ}$ for a representative CeSZ TBC system vs. the time alias hot hours in log-log format. The data points refer to $417 \mathrm{~h}$ and $835 \mathrm{~h}$ at temperature verified for a NiCoCrAlY bond-coated MCrAIY substrate with CeSZ topcoat. The related slope of the straight line according $\mathrm{t}^{1.0}$ provides information on the dominant mass transport mechanism for exclusively $Y$ indicating phase boundary control. During this time the Ce content, representing the "slope" of the residual elements in the $\mathrm{MZ}$, shows a conventional sub-parabolic mass transport.

The rate of $\mathrm{Y}$ enrichment is directly proportional to time according $\mathrm{t}^{1.0}$, while the agglomeration rates for $\mathrm{Cr}$, Ce and $\mathrm{Zr}$ decline and are following sub-parabola relationships of about $\mathrm{t}^{0.3}$ to $\mathrm{t}^{0.4}$. The direct relationship vs. time indicates a phase boundary ruled mass flow for $Y$. The hypothesis of the participation of a rate-determining phase-boundary reaction and the related characteristic linear kinetics are probably caused by the contribution 
of cerium. The hypothesis can be proved by converting the exclusive data of the Ce content in the MZ to their square root values. When the $\mathrm{Ce}+\mathrm{Zr}$ values are rearranged this way and the $\mathrm{Y}+\mathrm{Zr}$ data remain unchanged the resultant change in ordinate (Y-axis) causes a flatter slope of the data for CeSZ TBCs in double-log format as shown in Fig. 11. The resulting slope $\mathrm{n}$ of 0.5 representing a square root parabola relationship due to the "Ce conversion" is typical for a dominant diffusive mass transport. It provides indirect evidence of the hypothesis on the effect of Ce via generating a dominating phase boundary reaction within the entire transport process.

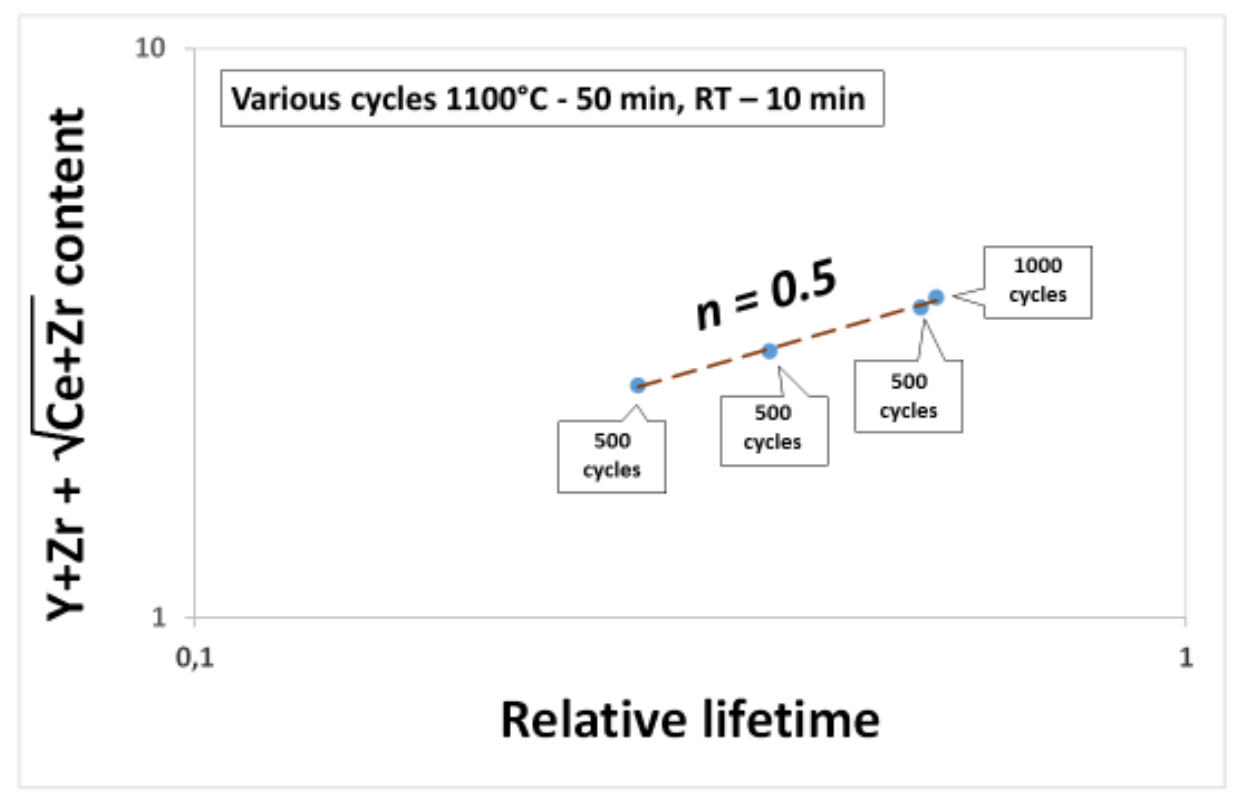

Fig. 11: The total contents of $\mathrm{Zr}$ and rare earths in the $\mathrm{MZ}$ in at.\%, where $\mathrm{Y}$ and $\mathrm{Zr}$ are balanced directly and $\mathrm{Ce}$ and $\mathrm{Zr}$ are taken jointly as square rooted values, as a function of the relative life for CeSZ top-coated systems in log-log format. The slope of the straight line is intended to provide information on the dominant mass transport by diffusion (according to square root relationship) and/or phase boundary control (according to direct relationship).

This finding is one more argument for phase boundary controlled mass transport in the system together with the decoding of the super-parabolic relationship of relative life versus REE content in the MZ in Fig. 4 . They demonstrate the result of a constant active phase boundary reaction driving a steady supply of $\mathrm{Y}$.

The comparatively low Y content in the MZ of CeSZ variants after $417 \mathrm{~h}$ (500 cycles) shown in Fig. 9 and the steady kinetics of $\mathrm{Y}$ accumulation indicate that a high $\mathrm{Y}$ content will be retained in the metal below. During this period, however, the $t$ '-phase stabilizing elements $Y$ and $C e$ are detracted from the TBC above. Both features favor prevention of separation failure at the Me/TGO interface and an impending destabilization of the strong tetragonal zirconia phase that triggers a mechanical decay of the CeSZ topcoat towards weak monoclinic and cubic phases.

The phase-boundary reaction has been defined so far by indirect evidence. A more manifest idea is given by a cross-sectional EDS spot analysis through the MZ of a FCT failed sample in Fig. 12. It shows the data for Zr, Al, and $\mathrm{Ce}$ while the $\mathrm{Cr}$ content (not shown here) stays approximately constant at $<0.5$ at.\% across the entire MZ. The $\mathrm{Y}$ content is of a similar order of magnitude, but rises slightly above 1 at\% close to the TBC. The high 
content of Al declines on approaching the TBC. In return, the Zr content increases accordingly which has been likewise observed in YSZ TBCs [24]. Only the content of Ce - the main stabilizing element for the tetragonal crystal structure of CeSZ - is virtually non-existent at the inward side of the MZ, but rises steeply just before the TBC.

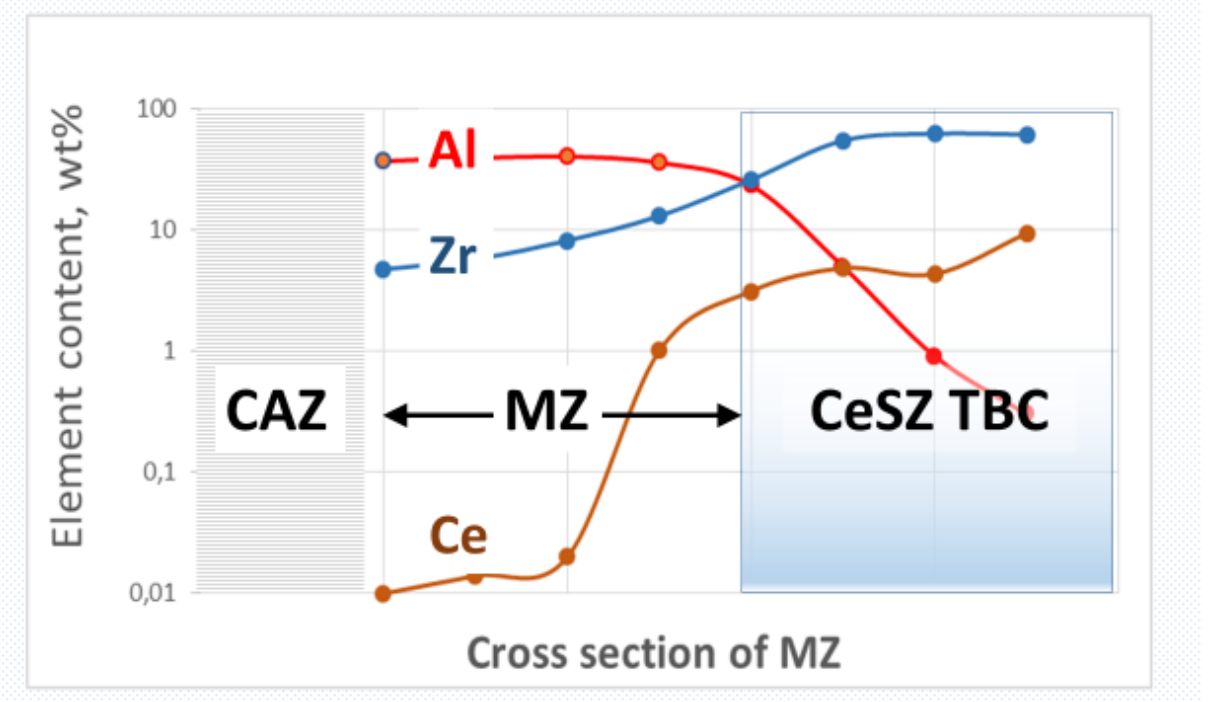

Fig. 12: EDS data for Al, Zr and Ce of a cross-section through the MZ of a CeSZ TBC system taken at a late stage of life. Note the sudden steep rise in Ce content on outward traversing the MZ [25].

In the context of this paragraph the possible formation of additional phases in the quaternary system $\mathrm{CeO}_{2}$ $\mathrm{Y}_{2} \mathrm{O}_{3}-\mathrm{Al}_{2} \mathrm{O}_{3}-\mathrm{ZrO}_{2}$ must not be overlooked. The system has been discussed at two different oxygen potentials. No extra phases besides the existing ones were reported after annealing the mixtures in air atmosphere. However, after annealing under vacuum, two additional phases of a ternary composition were identified as they were $\mathrm{CeO}_{2} \cdot 11 \mathrm{Al}_{2} \mathrm{O}_{3}$ and $\mathrm{CeAlO}_{3}$. Either the one or the other of the two phases was obtained alternatively as a function of the respective thermal treatments [26]. $\mathrm{CeAlO}_{3}$ is most preferably formed. It is a congruently melting perovskite compound which melts at $2100{ }^{\circ} \mathrm{C}$ under reducing conditions. It disintegrates, however, above $1275^{\circ} \mathrm{C}$ as soon as strong oxidizing conditions are given [27]. Possibly, this phase has also arisen during reactive EBPVD CeSZ processing under rough vacuum atmosphere conditions at $1000^{\circ} \mathrm{C}$ which have been conducted during CeSZ topcoat vapor deposition. This phase is assumed to stem from the partial reduction of $\mathrm{CeO}_{2}$ to $\mathrm{Ce}_{2} \mathrm{O}_{3}$ and conversion of $\mathrm{Ce}^{4+}$ to $\mathrm{Ce}^{3+}$ at $\sim 10^{-19} \mathrm{~atm}$ and $1100^{\circ} \mathrm{C}$ [28]. The conversion causes the bonding of $\mathrm{Ce}_{2} \mathrm{O}_{3}$ with $\mathrm{Al}_{2} \mathrm{O}_{3}$. The formation of this phase has not been investigated further in this study. By the way a technically relevant question could be posed based on these observations: Are CeSZ TBC systems produced by EBPVD at low gas pressures basically different in their mechanical and chemical properties from those produced by atmospheric plasma spraying due to their valence-induced inhomogeneity? This interesting question will not be discussed further in this study.

Following [29] $\mathrm{CeAlO}_{3}$ nucleation and growth takes place by a solid state reaction at the $\mathrm{Al}_{2} \mathrm{O}_{3} / \mathrm{CeO}_{2}$ interface which initiated the formation of an $\mathrm{Al}_{2} \mathrm{O}_{3} / \mathrm{AlCeO}_{3} / \mathrm{CeO}_{2}$ composite inter-layer. Their crystallographic 
orientation reportedly provided strong anchoring areas for $\mathrm{CeAlO}_{3} / \mathrm{CeO}_{2}$ "microdomains" which are regarded as impassable diffusion barriers for $\mathrm{Ce}^{4+}$.

Similar "microdomains" are presumably comparable to the diffusion barrier for Ce found in this study where Ce is tetravalent above and trivalent below. There obviously apparent trans-diffusion for Ce through this layer composite is hampered. The unrestricted diffusion of other elements in the $\mathrm{MZ}$, however, that do not change their valences above and below the barrier is likely. This model is likely to explain the structure in the MZ. Based on this information, a model idea of the oxygen potential gradients across the layers of EBPVD systems with YSZ and CeSZ topcoats is outlined in the following.

\subsection{The oxygen potential gradient}

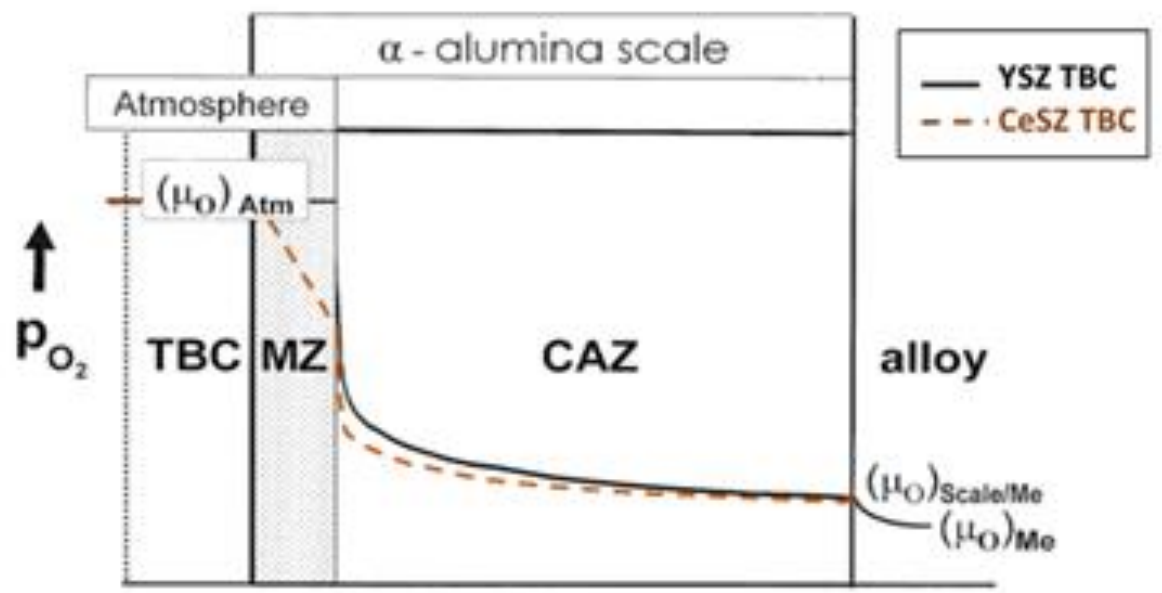

Fig. 13: Hypothetical scheme of the oxygen chemical potentials $\mu_{0}$ in log format versus the position within cross-sections of typical EBPVD TBC systems having either YSZ (solid line) or CeSZ topcoats (dotted line). The contour of the gradients in the CAZ (CAZ: columnar alumina zone of the TGO) is taken from M. Wada and co-workers [30]. The $p_{\mathrm{O}_{2}}$ related $\mathrm{Ce}^{4+} \leftrightarrow \mathrm{Ce}^{3+}$ conversion in the $\mathrm{MZ}$ of the CeSZ system [28] causes an obstacle for the passage of matter, which stands out as a kink in the $p_{\mathrm{O}_{2}}$ gradient of this system.

The scheme of the oxygen potential $p_{\mathrm{O}_{2}}$ in the scale of alumina forming alloys according to [30] has later been conveniently introduced in standard TBC systems having YSZ topcoats [3]. The course of the oxygen chemical potential extending from the surface at atmospheric pressure $\left(\mu_{0}\right)_{\text {Atm }}$ through the TBC, MZ and CAZ to the metal base $\left(\mu_{\mathrm{o}}\right)_{\mathrm{scale} / \mathrm{Me}}$ at a $p_{\mathrm{O}_{2}}$ of $\leq 10^{-26}$ atm at $1100^{\circ} \mathrm{C}$ is shown in Fig. 13 as a solid line. There it extends into the alloy $\left(\mu_{\mathrm{o}}\right)_{\mathrm{Me}}$ at a $p_{\mathrm{O}_{2}}$, for example, of $<10^{-26}$ atm.

The $\mathrm{MZ}$ is primarily a mixture of $\mathrm{Al} / \mathrm{Zr} / \mathrm{Y}$ oxides. Although $\mathrm{Zr}$ is representing only a minor portion in the $\mathrm{MZ}$ it rules the permeability for the atmosphere owing to the extended miscibility of zirconia with oxygen. It provides short-circuit diffusion paths for oxygen by itself. 
The scheme of the oxygen potential $p_{\mathrm{O}_{2}}$ of TBC systems having CeSZ topcoats differs from the course of the $p_{\mathrm{O}_{2}}$ of the YSZ systems. A complete change in the chemical equilibria within a TGO has been initiated due to the incorporation of $\mathrm{Ce}$. The $\mathrm{MZ}$ is in this case a mixture of $\mathrm{Al} / \mathrm{Ce} / \mathrm{Y} / \mathrm{Zr}$ oxides, wherein zirconia is the lowest portion. Possibly the inferior portion of zirconia is a rationale for the loss of the short-circuit diffusion paths for oxygen. Instead, the oxygen potential in the area of the MZ decreases with the distance from the CeSZ topcoat. An additional phase is assumed to have formed there, most probably a highly ordered $\mathrm{AlCeO}_{3}$ perovskite-type compound. And this compound will not show the same permeability for oxygen such as zirconia.

To form this compound, $\mathrm{CeO}_{2}$ must first be reduced to $\mathrm{Ce}_{2} \mathrm{O}_{3}$. A conversion of $\mathrm{Ce}^{4+}$ to $\mathrm{Ce}^{3+}$ takes place at $\sim 10^{-16}$ atm and $1100^{\circ} \mathrm{C}[28]$ according

$$
2 \mathrm{CeO}_{2}-\mathrm{O}_{2}^{\uparrow} \rightarrow \mathrm{Ce}_{2} \mathrm{O}_{3},
$$

the next step is the reaction with $\mathrm{Al}_{2} \mathrm{O}_{3}$ to $\mathrm{CeAlO}_{3}$ :

$$
\mathrm{Al}_{2} \mathrm{O}_{3}+\mathrm{Ce}_{2} \mathrm{O}_{3} \rightarrow 2 \mathrm{AlCeO}_{3}
$$

So the upper section of the potential gradient apparently ranges in the $M Z$ between atmospheric pressure and $10^{-16} \mathrm{~atm}$. The lower section of the potential gradient ranges below the $\mathrm{MZ}$ in the CAZ between $10^{-16} \mathrm{~atm}$ and the scale/alloy interface $\left(\mu_{\mathrm{o}}\right)_{\mathrm{scale} / \mathrm{Me}}$ at a $p_{\mathrm{O}_{2}}$ of $<10^{-26} \mathrm{~atm}$. While the oxygen potential extends only over the CAZ in the case of the YSZ systems, in CeSZ systems it occupies the full width of the TGO consisting of CAZ plus additional MZ. Accordingly the oxygen potential gradient created in CeSZ systems is lower compared to YSZ TBC systems.

The lower section of the potential gradient in the TGO of CeSZ systems also allows for lower diffusion rates in the TGO; consequently less $Y$ off-diffusion from the $Y$ reservoir in the bond coat is to be expected. This fact is also discussed in terms of prolonged lifetimes with Fig. 9. So the associated low oxygen pressure regime at the TGO growth front of $<10^{-26} \mathrm{~atm}$ at $1100^{\circ} \mathrm{C}$ can be maintained for longer times. Separation at the Me/TGO interface is less likely to happen, and even more so as the low $\mathrm{Y}$ accumulation rate declines even more when approaching the intermediate stage of life, as illustrated in Fig. 9.

The accumulation of $Y$ is small, but it is continuous, as indicated in Fig. 10 by the linear progression rate of $n=$ $t^{1}$, and hence significant in the course of life. The essential finding is that substantial portions of the $t^{2}$ stabilizing elements $\mathrm{Y}$ and $\mathrm{Ce}$ become depleted in the zirconia topcoat and enriched in the MZ probably due to $\Delta p_{\mathrm{O}_{2}}$ assisted diffusion. In the following the strong tetragonal zirconia phase in this zone transforms into the weaker monoclinic phase thus causing mechanical failure in the layer.

In summary of this paragraph, the accumulation kinetics of REEs $+\mathrm{Zr}$ in the MZ reveal that both YSZ and CeSZ systems undergo similar stages of early, intermediate and late life. Nevertheless, they differ with respect to their sources of $Y$ supply. In the case of $Y S Z$ systems, $Y$ is extracted from the metallic base (bond coat). Subsequent separation failure at the Me/TGO interface is likely as soon as the $Y$ reservoir - which accounts for a $p_{\mathrm{O}_{2}} \leq 10^{-26}$ - has been exhausted. - CeSZ systems primarily extract the t-stabilizing REEs $Y$ and Ce from the CeSZ topcoat during service. A successive lower mechanical stability of the "de-stabilized" zirconia topcoat results and culminates in TBC disintegration failure. 


\subsection{The substrate effect}

The present study clearly shows that the lives of EBPVD TBC Ni-base alloys can extremely be shortened up to about five times particularly for YSZ systems if alloyed with increasing contents of refractory elements e. g. of $\mathrm{Mo}, \mathrm{Re}, \mathrm{Ta}$, and W, as shown in Fig. 4. Similar refractory elements, which improve the high temperature capability and creep resistance of super alloys are suspected to cause earlier failure of the TBC systems. There is obviously no premature failure in these cases, but a shortened life cycle, always represented by early, intermediate, and late stages of life. The "uniform lifetime relationships" in Figs. 5 and 11 already suggest, by virtue of their square root relationships, that the different lifetimes are caused by differing diffusion rates and phase boundary controlled mass fluxes in the TGO. -

By the way the lifetime of TBC systems can be extremely extended by (additional) doping with $\mathrm{Hf}$, as already suggested in the introduction. This "benefit" is caused by using Hf containing super alloys (e. g. René 142) or Hfcontaining bond coats. They switch to a different type of oxidation behavior as well as other failure mechanisms that can cause superior service lives.

Obviously the detrimental influence of high diffusion rates in the scales on life is less if CeSZ topcoats have been applied instead of YSZ topcoats.

The focus of the discussion is now on the influence of these substrate elements on the accumulation rate of $\mathrm{REE}+\mathrm{Zr}$ elements in the $\mathrm{MZ}$ and the resultant diffusivities.

In the MZ, no contents of refractory elements were initially detected via EDS analysis. So they have seemingly not penetrated the TGO either. On the other hand, the oxides of refractory elements have reportedly been found in the upper layer of TGOs of alumina-forming Ni-base alloys being alloyed with similar contents of refractory elements [31]. Thus, some passage of refractory metal cations through the TGO is hypothesized to be likely, their concentration, however, is possibly below the detection limit of $x$-ray microanalysis in the alumina lattice. They settle there as "stowaways". However, the concentration of these cations is dependent on the concentration of available cation vacancies; and it will raise the more aliovalent cations of the metal substrate will enter the TGO. On the other side the corresponding vacancy concentration decreases as a result of a $p_{\mathrm{O}_{2}}$ reduction following equation (3). Thus the setback in lifetime is assumed to be due to the release of very small amounts of refractory element cations in alumina from the substrates. Presumably they have entered the $\alpha$-alumina crystal lattice after having passed through the bond coat. There they interact with the existing point defects as vacancies $\mathrm{V}_{\mathrm{Al}}{ }^{\prime}$, electrons, electron holes and cations. - One of the rules for defect reactions in stoichiometric ionic compounds is the preservation of the regular site ratio: this also applies to $\alpha$ $\mathrm{Al}_{2} \mathrm{O}_{3}$ having cations $\mathrm{M}_{A l}$ and cation vacancies $V_{A l}$ and anions $\mathrm{X}_{O}$ and anion vacancies $V_{O}$ according

$$
\left(\mathrm{M}_{\mathrm{Al}}+V_{\mathrm{Al}}\right):\left(\mathrm{X}_{O}+\mathrm{V}_{O}\right)=2: 3 \text {. }
$$

The ratio implies that in view of the electro-neutrality an equivalent amount of +-type and --type point defect sites exists within the TGO establishing $n$-type character towards the bottom and $p$-type towards the exterior. The defect reactions running at the bottom most likely exert an effect on the defect concentration towards the exterior TGO including the alumina matrix of the MZ. The increase in point defects is most likely balanced by the accumulation of REE + Zr corresponding to thermodynamic equilibrium conditions. In order to demonstrate the dynamics of this relationship, plausibly based on inter-diffusion, the refractory element content of the 
substrate alloys - given as square root values - is shown in Fig. 14 as a function of the $\mathrm{Y}+\mathrm{Zr}$ content in the $M Z$ on same substrates. The straight line of the function confirms a square root relationship between $\mathrm{Y}+\mathrm{Zr}$ content in the $\mathrm{MZ}$ and refractory element content in the substrate; it thus gives an indirect evidence for the action of diffusion-controlled processes between the layers. Therefore the service life of TBCs will be shorter.

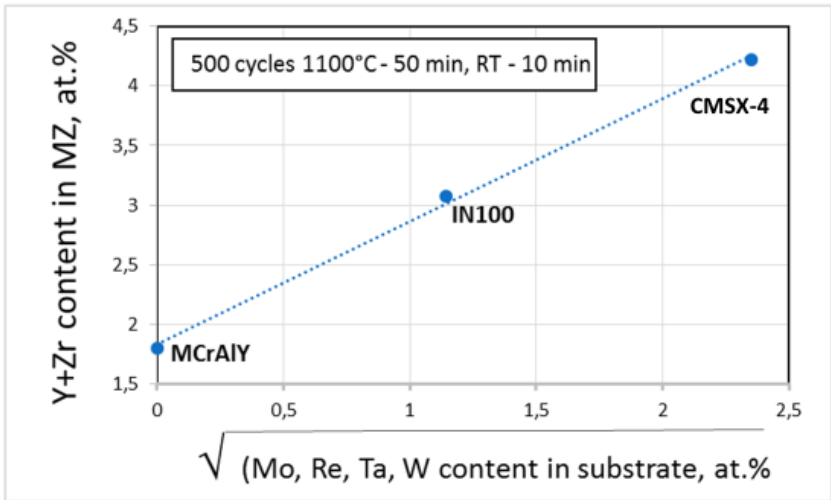

Fig. 14: Refractory element content (square root values) of YSZ top-coated Ni-base alloy vs. Y + Zr content in the $\mathrm{MZ}$ after exposure to identical hot hours $\left(417 \mathrm{~h}\right.$ at $\left.1100^{\circ} \mathrm{C}\right)$. The straight line representing a square root relationship indicates outward diffusion controlled transport of the refractory elements in dependence of the cation vacancy concentration.

According equation (5) it follows that a limited number of Al vacancies $V_{\mathrm{Al}}$ acts as "vehicles" offering the transfer of 3-charged elements like $\mathrm{Al}^{3+}$ or $\mathrm{Y}^{3+}$ through the cation sub-lattice. Other differently charged cations can be transported either, in the present case refractory element cations can be transferred as well. However the refractory elements are 4-charged at least. For reasons of electro-neutrality additional vacancies in the lattice must be created. The accumulation rate of $Y+Z r$ in the $M Z$ is accelerated in proportion to the rise in the concentration of vacancies.

The influence of the CeSZ topcoat on the accumulation rate of the elements $\mathrm{Ce}+\mathrm{Y}+\mathrm{Zr}$ in the $\mathrm{MZ}$ as a function of the concentration of the refractory elements in the substrates is by large the same as that of the YSZ, see Fig. 12. A closer look at the differences between the Figs. 14 and 15 however reveals two special features.

(i) In order to be able to represent the square root parabolic relationship of the accumulative elements versus the concentration of the refractory elements of the substrate as a linear line, the content of $\mathrm{Ce}$ in the ordinate should be plotted as a square root value as done in analogy to Fig. 11. So the contribution of cerium can once more be presented as a decisive member in arranging a dominant interfacial transport reaction in line with linear kinetics. So a simultaneous action of the transport steps via diffusion or boundary effects can be assumed, which are ruled either by the concentration of point defects in the lattice or also by additional phase boundary reactions.

(ii) The difference between the minimum and maximum $R E E+Y$ contents with respect to the ordinates is the factor of about 2.5 for YSZ TBCs, but only 1.4 for CeSZ TBCs. The clear difference shows that the substrate effect in CeSZ TBC systems is significantly less pronounced than in YSZ systems. It is due to the lower oxygen potential gradient and the related lower diffusion rates in the TGO. 
Despite the difference in substrate effects, however, it is assumed that due to the same processing routes the very initial concentration of Al vacancies in each one of the YSZ and CeSZ systems has been identical.

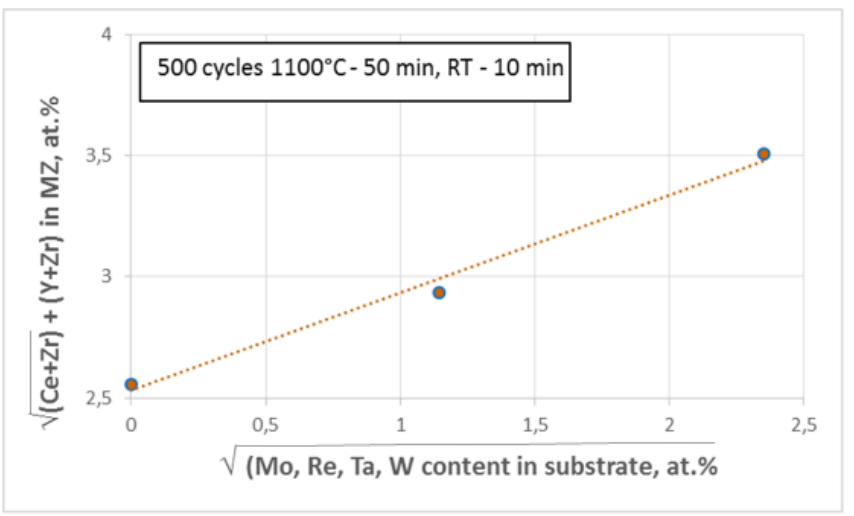

Fig. 15: Refractory element content (square root values) of CeSZ top-coated Ni-base alloy vs. concentration of $\mathrm{Y}+\mathrm{Zr}+(\mathrm{Ce}+\mathrm{Zr})^{0.5}$ in the $\mathrm{MZ}$ after exposure to identical hot hours $\left(417 \mathrm{~h}\right.$ at $\left.1100^{\circ} \mathrm{C}\right)$. The straight line indicates a square root relationship corresponding to the joint mass transport via diffusion plus phase boundary control.

The given arguments explain the mechanism of the "substrate effect" which is caused by the contents of the refractory elements in the substrates. The varying intensities of the substrate effect, however, depend on the different oxygen potential gradients in the TGO; they are caused by the two $\mathrm{Y}$ or Ce+Y tetragonally-stabilized zirconia topcoats.

\section{Summary}

The FCT lifetime of EBPVD TBC systems and their failure mode at $1100^{\circ} \mathrm{C}$ were determined on Ni-base alloy samples comprising YSZ or CeSZ topcoats. The samples have habitually been produced under identical conditions and the respective route of manufacture of the YSZ and CeSZ topcoats is pointed out. The service life of both sample variants is essentially based on chemical aspects within the TGO and in particular in the MZ. They are already settled by the composition of the bond coat, the zirconia topcoat, and the respective substrate.

The lifetime is determined by diffusion processes. The rate of diffusion depends on the mobility of the elements involved, the concentration of lattice point defects in the TGO, which in turn depends on the oxygen potential at the Me/TGO interface and the quantity of dissolved refractory elements, and the oxygen potential gradient in the TGO as the driving force for mass flow. The chemical aspects are:

- composition of NiCoCrAlY bond coats: High Cr contents in the bond coat are problematic. The more agile $\mathrm{Cr}$ ions replace $\mathrm{Al}$ ions and occupy regular cation sites in the alumina lattice, they are causing shorter lifetimes. 
- $\quad$ ziconia topcoat: In TBC systems with a YSZ topcoat, a typical high oxygen potential gradient is provided in the TGO which dominates the diffusion activity. It causes the continual off-diffusion of $Y$ from the bond coat to the $M Z$, accompanied by an increase in the oxygen potential until reaching the dissociation potential of alumina at the Me/TGO interface. There, it drives separation failure to occur. - In TBC systems with a CeSZ topcoat, a minor oxygen potential gradient in the TGO is provided. For that reason a comparatively lower oxygen potential is maintained in the Me/TGO and the adjoining bond coat. Thereby, the off-diffusion of $Y$ from the bond coat is reduced, and related separation failure at the Me/TGO is unlikely. Instead, dominant off-diffusion of $Y$ and Ce from the topcoat to the $\mathrm{MZ}$ is activated; it causes depletion of the zirconia on its $t^{\prime}$-stabilizing elements $\mathrm{Y}$ and Ce which triggers TBC disintegration failure in a now mechanically weaker topcoat.

- respective substrate: The lattice point defect concentration in the TGO is increased on super alloy substrates that are strongly alloyed with refractory elements. This makes the diffusive flux for the rare earth elements in the TGO faster and the lifetime shorter. This substrate effect is more pronounced in YSZ systems than in CeSZ systems.

\section{Appendix}

\section{Feasibility of EBPVD YSZ and CeSZ topcoats}

The favorable feasibility of YSZ topcoats via reactive electron beam evaporation, which has become a prominent industrially established technology, can be above all ascribed to particular material properties of the YSZ layer materials:

1. $\mathrm{Y}_{2} \mathrm{O}_{3}$ and $\mathrm{ZrO}_{2}$ are part of a eutectic system that shows limited mixed crystal regions of appropriate tetragonal phase.

2. Their ranges of stoichiometry are sufficiently stable at all typical temperatures and oxygen pressures of relevance.

3. The boiling points and vapor pressures of both oxides are almost the same.

Therefore, a mixture of powders of both oxides can simply be compacted and be used as source material for zirconia coating deposition. In this way YSZ TBCs are advantageously produced via single-crucible reactive electron beam evaporation.

However, the feasibility of CeSZ TBCs (consisting of $\mathrm{ZrO}_{2}-25 \mathrm{CeO}_{2}-2.5 \mathrm{Y}_{2} \mathrm{O}_{3}$ in wt.\%) by reactive electron beam evaporation is problematic. $\mathrm{CeO}_{2}$ and $\mathrm{Y}_{2} \mathrm{O}_{3}$ form mutually wide mixed crystal regions but homogeneous phase regions depend on the temperature and the oxygen pressure. The vapor pressure of ceria differs by $>$ four orders of magnitude from that of yttria and zirconia. Hence the layers obtainable by single-crucible evaporation from a Ce-Y-Zr oxide source show a high scattering of the composition; as a consequence a stepwise loss and degradation of those layers is observed in service. The step-wise loss is due to the fluctuations of the composition across the thickness of the TBC which cause alternating inter-layers of weak and stronger phases e. g. m-,c- and most appropriate t'-phase zirconia. [2]. 
This problem has been circumvented at DLR by applying the "jumping beam method" using the simultaneous evaporation of two different source compositions put in two adjacent crucibles. One of the crucibles is charged with an appropriate $\mathrm{ZrO}_{2}-\mathrm{Y}_{2} \mathrm{O}_{3}$ ingot. The other crucible should be loaded with the "right" Ce containing ingot; in case of a ceria ingot, however, there arise fundamental questions about the feasibility of reproducible and homogeneous CeSZ TBCs: These relate to diverse equilibria required between various phases to be expected. These are two cerium oxide phases which can be liquid or solid or both $\left(\mathrm{CeO}_{2}\right.$ melting point $2400^{\circ} \mathrm{C}, \mathrm{Ce}_{2} \mathrm{O}_{3} \leq$ $2210^{\circ} \mathrm{C}$, and a low-melting eutectic at $795^{\circ} \mathrm{C}$ of both ceria phases). They may evaporate and/or sublimate, depending on the temperature and the oxygen pressure in the coater. With respect to the Gibbs` phase rule, the number of phases involved in this scenery is too high.

Reactive EBPVD processing of CeSZ coatings compliant with the Gibbs` phase rule can well be achieved by means of dual-crucible jumping beam evaporation, e. g. in the following way: a ceramic $\mathrm{ZrO}_{2}-\mathrm{Y}_{2} \mathrm{O}_{3}$ ingot of appropriate composition is evaporated from the one crucible as just mentioned; and simultaneously pure cerium - instead of a $\mathrm{Ce}_{2} \mathrm{O}_{3}$ source that cannot be provided as a storable ingot* - is acting as the supplementary vapor source in the twin crucible. Meanwhile the oxygen partial pressure in the coater serves as a decisive "manipulated variable", which has to be controlled during the reactive coating processing.

It should be noted that the lifetime results in this study are based on FCT experiments in calm air in a lab environment. If the use of CeSZ TBC systems under hot gas conditions for turbine blade applications should be considered, then the influence of the relatively high vapor pressure of ceria should be kept in mind.

*) The expertise of T. Reetz, Reetz GmbH Berlin for optimal coating process management with CeSZ has been appreciatively employed.

Acknowledgments Without the inspiring insightful discussions with Wolfgang Braue and his advantageous proofreading, this work would not have been created. The author also thanks Uwe Schulz for many years of fruitful cooperation.

\section{References}

1. N.P. Padture, M. Gell, and E.H. Jordan, Thermal Barrier Coatings for Gas-Turbine Applications, Science 269 (2002) 5566; 280-84.

2. Ji-S. Wang, S.-L. Zhang, T. Liu, C.-J. Li, C.-X. Li, and G.-J. Yang, Dominant effect of particle size on the $\mathrm{CeO}_{2}$ preferential evaporation during plasma spraying of $\mathrm{La}_{2} \mathrm{Ce}_{2} \mathrm{O}_{7}$, Journal of the European Ceramic Society 17 (2017) 1577-85.

3. U. Schulz, K. Fritscher, C. Leyens, M. Peters, and W.A. Kaysser, The Thermocyclic Behavior of Differently Stabilized and Structured EB-PVD TBCs, Journal of Metals 49 (1992)e-JOM, 1-10. 
4. K. Fritscher, C.-J. Kröder, and U. Schulz, Adherence and Failure of an EBPVD/7YSZ Coating on a $\beta /{ }^{-N i C r A l ~ S u b s t r a t e: ~ A ~ P i l o t ~ S t u d y, ~ O x i d a t i o n ~ o f ~ M e t a l s ~} 86$ (2016)279-98.

5. K. Fritscher, W. Braue, and U. Schulz, Assessment of Cyclic Lifetime of NiCoCrAlY/ZrO ${ }_{2}-$ Based EB-PVD TBC Systems via Reactive Element Enrichment in the Mixed Zone of the TGO Scale, Metallurgical and Materials Transactions A 44 (2013)2070-82.

6. U. Kaden, PhD thesis, RWTH Aachen, Werkstoffwissenschaftliche Schriftenreihe, $\mathbf{5 6}$ (2003) ISBN 3-86130-094-X.

7. K. Fritscher, unpublished results 2003.

8. J.A. Ruud, A. Bartz, M.P. Borom, and C.A. Johnson, Strength degradation and failure mechanisms of electron-beam physical-vapor-deposited thermal barrier coatings. Journal of the American Ceramic Society 84 (2001) 1554-52.

9. D. Zimmermann, M. Bobeth, M. Rühle, and D.R. Clarke, Oxidation-induced cavity formation in binary $\beta$-NiAl alloys, Zeitschrift für Metallkunde 95 (2004) 84-90.

10. J.C. Yang, K. Nadarzinski, E. Schumann, and M. Rühle, Electron microscopy studies of NiAl/ $\gamma$ $\mathrm{Al}_{2} \mathrm{O}_{3}$ interfaces, Scripta Metallurgica et Materialia 33 (1995) 1043-48.

11. H. Schmalzried, Solid State Reactions, $2^{\text {nd }}$ edition, Verlag Chemie, Weinheim (1981).

12. P. Saltykov, O.Fabrichnaya, J. Goczewski, and F. Aldinger, Thermodynamic modeling of oxidation of Al-Cr-Ni alloys, Journal of Alloys and Compounds 381 (2004) 99-113.

13. D. Naumenko, V. Kochubey, L. Niewolak, A. Dymiati, L. Mayer, L. Singheiser, and W.J. Quadakkers, Modification of alumina scale formation on FeCrAlY alloys by minor additions of group IVa elements, Journal of Materials Science 43 (2008) 4550-60.

14. U. Kolitsch, H.J. Seifert, T. Ludwig, and F. Aldinger, Phase equilibria and crystal chemistry in the $\mathrm{Y}_{2} \mathrm{O}_{3}-\mathrm{Al}_{2} \mathrm{O}_{3}-\mathrm{SiO}_{2}$ system, Journal of Materials Research 14 (1999) 447-455.

15. J. Balmain and A.M. Huntz, Improvement of the application of an electrochemical method for the determination of transport properties of an $\alpha$-alumina scale. Part II: Influence of yttrium and palladium on alumina scales developed on a $\beta-N i A l$ alloy, Oxidation of Metals 46 (1996) 213-34.

16. G.J. Santoro, D.L. Deadmore, and C.E. Lowell, Oxidation of alloys in nickel-aluminum system with third- element additions of chromium, silicon, and titanium at $1100^{\circ} \mathrm{C}$, NASA TN D-6414, July 1971.

17. M.W. Brumm and H.J. Grabke: The oxidation behaviour of NiAl. I. Phase transformations in the alumina scale during oxidation of NiAl and NiAl-Cr alloys, Corrosion Science 33 (1992)16771690.

18. B.A. Pint, B.A. Nagaraj, and M.A. Rosenzweig, Evaluation of TBC-Coated $\beta$-NiAl Substrates Without a Bond Coat, published in High Temperature Coatings II, eds.: N. Dahorte, J.M. Hampikian, J.J. Stiglich, TMS, Warrendale, Pa. 1996, p.163-74. 
19. B. Pint, in Proceedings of the John Stringer Symposium on High Temperature Corrosion, (5-8 Nov. 2001) pp. 9-19.

20. K. Bedu-Amissah, J.M. Rickman, H.M. Chan, and M.P. Harmer, Grain-Boundary Diffusion of $\mathrm{Cr}$ in Pure and Y-Doped Alumina, Journal of the American Ceramic Society 90 (2007)1551-1555.

21. E. Wessel, V. Kochubey, D. Naumenko, L. Niewolak, L. Singheiser, and W.J. Quadakkers, Effect of $\mathrm{Zr}$ additions on the microstructure of the alumina scales on FeCrAlY-alloys, Scripta Materialia 51 (2004) 987-992.

22. W.J. Quadakkers, and M.J. Bennett, Oxidation induced lifetime limits of thin walled, iron based, alumina forming, oxide dispersion strengthened alloy components, Materials Science and Technology 10 (1994)126-31.

23. A. Cuneyt Tas and M. Akine, Phase Relations in the System $\mathrm{Ce}_{2} \mathrm{O}_{3}-\mathrm{Al}_{2} \mathrm{O}_{3}$ in Inert and Reducing Atmospheres, Journal of the American Ceramic Society 77 (1994) 2961-67.

24. C.G. Levi, E. Sommer, S.G. Terry, A. Catanoiu, and M. Rühle, Alumina Grown during Deposition of Thermal Barrier Coatings on NiCrAlY, Journal of the American Ceramic Society 86 (2003) 67685.

25. H. Lau, unpublished result 2013.

26. A.V. Sherchenko, E.V. Dudnik, A.K. Ruban, V.P. Redko, and L.M. Lopato, Sintering of selfreinforced ceramics in the $\mathrm{CeO}_{2}-\mathrm{Y}_{2} \mathrm{O}_{3}-\mathrm{Al}_{2} \mathrm{O}_{3}-\mathrm{ZrO}_{2}$ system, Powder Metallurgy and Metal Ceramics 49 (2010) 42-49.

27. T. Shishido, Y. Zheng, A. Saito, H. Horiuchi, K. Kudou, S. Okada, and T. Fukuda, Microstructure, thermal properties, and hardness of the $\mathrm{CeMO}_{3}(\mathrm{M}=\mathrm{Al}, \mathrm{Ge})$ synthesized by arc-melting method, Journal of Alloys and Compounds 260 (1997) 88-92.

28. M. Zinkevich, D. Djurovic, and F. Aldinger, Thermodynamic modelling of the cerium-oxygen system, Solid State lonics 177 (2006) 989-1001.

29. S. Humbert, A. Colin, I. Menceaux, F. Oudet, and P. Courtine, "Simultaneous atmosphere and temperature cycling of three-way automotive exhaust catalysts", A. Frennet, J.-M. Bastin (Eds.) Catalysis and Automotive Pollution Control III, Studies in: Surface Science and Catalysis, Vol. 96 (1995) Elsevier Science.

30. M.M. Wada, T. Matsudaira, and S. Kitaoka, Mutual grain-boundary transport of aluminum and oxygen in polycrystalline $\mathrm{Al}_{2} \mathrm{O}_{3}$ under oxygen potential gradients at high temperatures, Journal of the Ceramic Society of Japan 119 (2011) 832-839.

31. K. Fritscher, O. Schubert, C. Leyens, and U. Schulz, Short-time Oxidation of Cast $\mathrm{V} / \mathrm{\gamma}^{\prime}-\mathrm{Ni}-\mathrm{Cr}-\mathrm{Al}-$ Ta-Re Alloys at $1000^{\circ} \mathrm{C}$, Oxidation of Metals 78 (2012) 63-82. 
